OPEN ACCESS

Edited by:

Diego Mantovani,

Laval University, Canada

Reviewed by:

Laia Tolosa

Instituto de Investigación

Sanitaria La Fe, Spain

Kazuo Takayama,

Kyoto University, Japan

${ }^{*}$ Correspondence: Qianqian Xu

16250982@life.hkbu.edu.hk

Specialty section:

This article was submitted to

Tissue Engineering and Regenerative

Medicine,

a section of the journal

Frontiers in Bioengineering and

Biotechnology

Received: 24 June 2021

Accepted: 30 August 2021

Published: 24 September 2021

Citation:

Xu Q (2021) Human Three-

Dimensional Hepatic Models: Cell Type

Variety and

Corresponding Applications.

Front. Bioeng. Biotechnol. 9:730008.

doi: $10.3389 /$ fbioe. 2021.730008

\section{Human Three-Dimensional Hepatic Models: Cell Type Variety and Corresponding Applications}

\author{
Qianqian $X u^{*}$ \\ School of Chinese Medicine, and Centre for Cancer and Inflammation Research, Hong Kong Baptist University, Hong Kong, \\ China
}

Owing to retained hepatic phenotypes and functions, human three-dimensional (3D) hepatic models established with diverse hepatic cell types are thought to recoup the gaps in drug development and disease modeling limited by a conventional twodimensional (2D) cell culture system and species-specific variability in drug metabolizing enzymes and transporters. Primary human hepatocytes, human hepatic cancer cell lines, and human stem cell-derived hepatocyte-like cells are three main hepatic cell types used in current models and exhibit divergent hepatic phenotypes. Primary human hepatocytes derived from healthy hepatic parenchyma resemble in vivo-like genetic and metabolic profiling. Human hepatic cancer cell lines are unlimitedly reproducible and tumorigenic. Stem cell-derived hepatocyte-like cells derived from patients are promising to retain the donor's genetic background. It has been suggested in some studies that unique properties of cell types endue them with benefits in different research fields of in vitro 3D modeling paradigm. For instance, the primary human hepatocyte was thought to be the gold standard for hepatotoxicity study, and stem cell-derived hepatocyte-like cells have taken a main role in personalized medicine and regenerative medicine. However, the comprehensive review focuses on the hepatic cell type variety, and corresponding applications in 3D models are sparse. Therefore, this review summarizes the characteristics of different cell types and discusses opportunities of different cell types in drug development, liver disease modeling, and liver transplantation.

Keywords: in vitro 3D model, drug development, liver disease, hepatocyte transplantation, hepatic cell types

\section{INTRODUCTION}

The liver is one of the largest organs in the body and plays a critical role in drug metabolism. Hepatic disease accounts for approximately 2 million deaths per year worldwide, of which 1 million are due to complications of cirrhosis and 1 million are due to viral hepatitis and hepatocellular carcinoma (Asrani et al., 2019). Establishing a suitable modeling paradigm is essential for preclinical drug development and disease study. However, species-specific drug metabolizing enzymes and transporters (DMETs) involved in drug absorption, distribution, metabolism, and excretion alter the drug metabolic pathway, hampering the application of animal models in human toxicity prediction (Olson et al., 2000; Cheung and Gonzalez, 2008). Meanwhile, conventional 2D monolayer culture has been proved with uniform exposure to signaling cues and nutrients and less cell-cell and cell-matrix interactions. Thus, rapid dedifferentiation and loss of cellular 
phenotype were observed in a $2 \mathrm{D}$ primary human hepatocyte model, manifesting as a low expression level of key DMETs and decreased albumin production (Rowe et al., 2013). Earliest perturbations on the transcript level in primary hepatocytes were observed after $30 \mathrm{~min}$, and more than 4,000 transcripts were differentially expressed during the first $24 \mathrm{~h}$ of culture, significantly affecting pathways involved in the tricarboxylic acid cycle, oxidative phosphorylation, and urea synthesis (Lauschke et al., 2016).

To fill the research gap, development of 3D models that resemble the structure of in vivo tissue, imitate cell-cell and cell-matrix interactions, and provide an in vivo-like biophysical environment with diverse novel techniques is ongoing. Compared to $2 \mathrm{D}$ models, 3D models are promising to replicate morphological and functional features of in vivo tissue and retain cellular phenotypes in a relatively long term for repetitive time course measurement and sampling of various endpoints (Bell et al., 2017; Lauschke et al., 2019; Nuciforo and Heim, 2021). Owing to the above, 3D hepatic models show unique benefits in fields of drug development, disease modeling, and liver transplantation. Current breakthroughs on 3D hepatic models include using scaffold-free or scaffold-based culture techniques in the establishment of spheroids, organoids (henceforth defined as an in vitro 3D structure which harbors cells with differentiation potential and organ functionality, such as tissue-resident human adult stem cells (hASCs), human embryonic stem cells (hESCs), or human induced pluripotent stem cells (hiPSCs) (Huch and Koo, 2015)), micropatterned co-culture (MPCC) models, and liveron-a-chip models. Hepatic spheroids are spherical multicellular aggregation which can be generated from one or more hepatic cell types but do not undergo self-organization. The unique spherical structure results in gradient exposure of cells to nutrients, gases, growth factors, and signaling factors from the outside to the center. Therefore, it particularly benefits modeling of spatial zonation of hepatic lobules and the natural architecture of hepatic solid tumor (Cui et al., 2017). Meanwhile, the longevity of this model system is typically limited by the development of a hypoxic and necrotic core with the proliferating cells over time, limiting the diffusion of oxygen into its core (Cox et al., 2020). It was reported that hypoxia would take place in spheroids up to $100-200 \mu \mathrm{m}$ (Glicklis et al., 2004; Grimes et al., 2014). To create organoids, stem cells are firstly co-differentiated into epithelial and mesenchymal lineages to form spheroids. These spheroids are then embedded in Matrigel and cultured with retinoic acid to further mature. Organoids thus possess self-renewal and self-organization properties that provide a similar composition and architecture to primary tissue and are more suitable than spheroids for investigating long-term processes involving development and degeneration (Huch and Koo, 2015). The MPCC model is established via co-culturing primary human hepatocytes with 3T3-J2 murine embryonic fibroblasts. In contrast to pure $\mathrm{PHH}$ monolayers that display a rapid decline in phenotypic functions, this co-culture platform allows interaction between PHH and non-parenchymal cells, maintaining high levels of cytochrome P450 (CYP450) and phase II conjugation enzymes activities for more than 4 weeks (Khetani et al., 2013). The liver-on-a-chip model is created via incorporating microchip fabrication methods into a microfluidic perfusion system. This model contains microchannels that introduce nutrition, oxygen, and signaling cues while removing waste continuously and continuously perfused micrometer-sized cell culture chambers to simulate tissue- or organ-level physicochemical microenvironments. Thus, it is superior in modeling the liver sinusoid, creating a more realistic and dynamic zone-specific culture environment (Gupta et al., 2016). In vivo, a hepatic extracellular matrix (ECM) supports structure and signaling trafficking, maintains hepatocyte polarity, and provides the microenvironment for interaction of hepatocyte and immune cells via integrins and other ECM receptors (Treyer and Müsch, 2013; Gissen and Arias, 2015; McQuitty et al., 2020). Owing to its essential role in maintaining hepatic function and disease progression, the ECM should be involved in the establishment of in vivo-like 3D models. Scaffold-free techniques are independent of biomaterials imitating the hepatic ECM. Instead, they provide conditions promoting cells to produce their own ECM, which can be achieved via self-aggregation of cells by gravity in hanging drops, culture on an ultra-low attachment surface, large-scale generation by perfused stirred-tank bioreactors, and magnetic levitation of cells preloaded with magnetic nanoparticles. Scaffold-based techniques utilize natural or synthetic external cell anchoring systems that mimic the ECM to facilitate the formation of cell-cell contacts and tissue organization. Common scaffoldbased 3D culture paradigms include micropatterned co-culture, microcarrier bead configuration, matrix-embedded, hollow fiber bioreactors, and microfluidics systems (Underhill and Khetani, 2018; Lauschke et al., 2019; Mizoi et al., 2020). Furthermore, 3D bioprinting has been applied as a precise layering method to create scaffolds with a tightly controlled architecture and posit cells or spheroids as building blocks in a specified spatial arrangement necessary for tissue formation (Derakhshanfar et al., 2018; Ma et al., 2018). Compared with scaffold-free techniques, scaffold-based culture configurations have the potential to provide a more delicate biophysical environment for 3D models.

Three hepatic cell types are mainly involved in the above paradigms: primary human hepatocytes isolated from hepatic parenchyma, human hepatic cancer cell lines obtained from hepatocellular carcinoma, and human stem cell-derived hepatocyte-like cells. Different cell types possess unique genetic and protein expression profiles and thus may take specific advantages in divergent research fields. To ensure 3D cell models faithfully recapitulate drug dose response or disease nature, it is essential to select a suitable cell type in the corresponding experiment. Though abundant human 3D hepatic models based on various cell types have been developed, a study that comprehensively summarizes and elaborates this topic is lacking. Therefore, this review is aimed at demonstrating characteristics of different cell types used in current 3D hepatic models and providing guidance for choosing a cell culture system to establish the corresponding 3D model. 


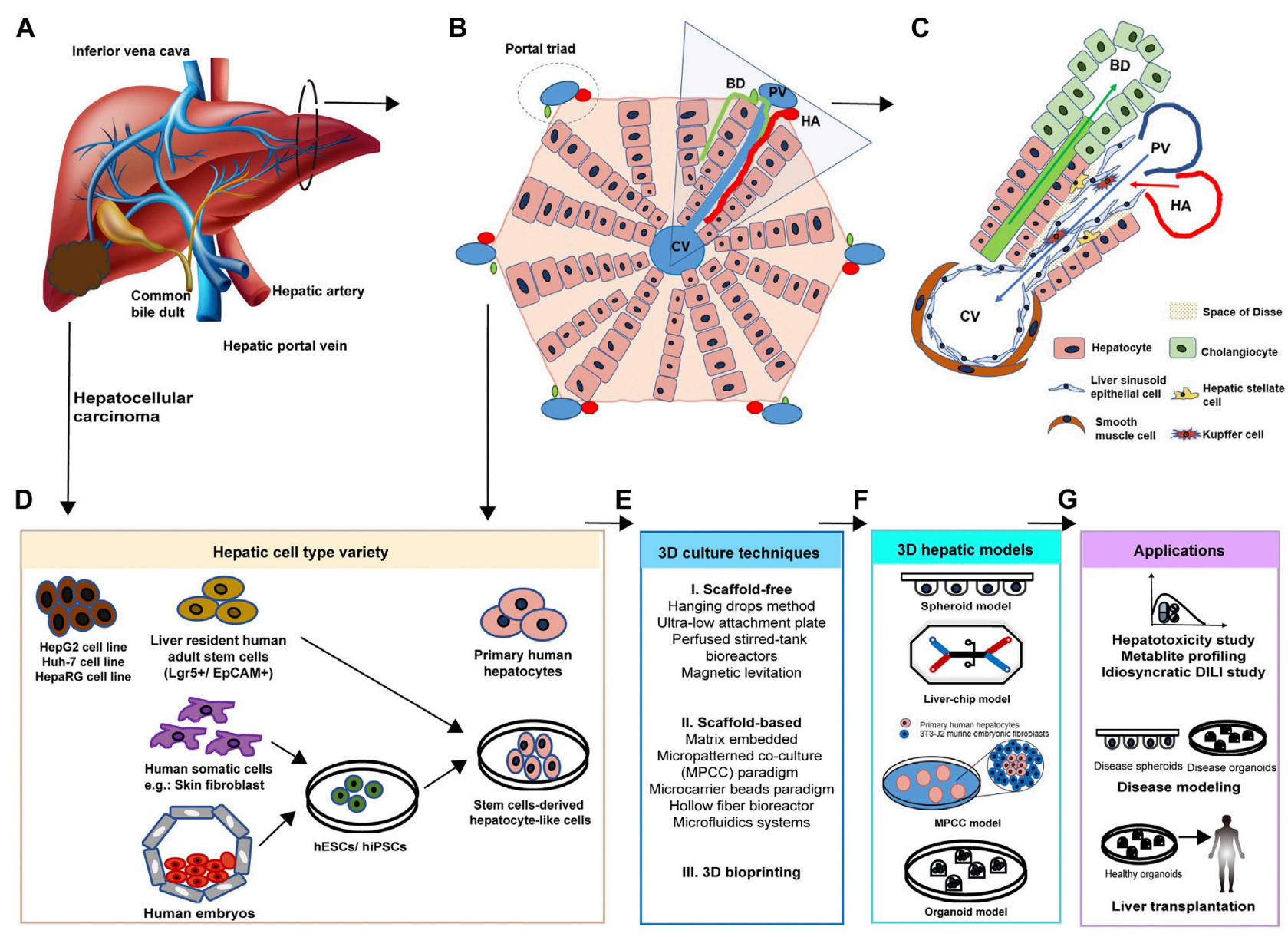

FIGURE 1 | Cellular composition of the liver. (A) Gross structure and blood supplies of the liver. The liver is a dark reddish-brown organ supplied by two distinct blood sources: oxygenated blood from the hepatic artery (HA) and nutrient-rich blood from the hepatic portal vein (PV). (B) Hepatic lobules are composed of hepatocytes arranged in linear cords radiating out from the central vein (CV) and portal triads including the bile duct (BD), HA, and PV. (C) The representative hepatic functional unit in hexagonal hepatic lobules is composed of diverse cell types. Besides parenchymal cells, non-parenchymal cells also support the hepatic structure and function. Hepatic blood vessels are lined by specialized fenestrated liver sinusoidal endothelial cells (LSECs). Kupffer cells (KCs) are macrophages found in the sinusoids. Hepatic stellate cells (HSCs) locate in the space of Disse. Cholangiocytes line the bile ducts. (D) Hepatic cell types used in in vitro 3D models can be obtained from healthy hepatic tissue, hepatocellular carcinoma, induced somatic cells, and human embryos. (E) Advanced 3D culture techniques. Scaffold-free, scaffold-based, and 3D bioprinting techniques are applied to build 3D models. (F) Current 3D hepatic models include spheroid, liver-on-a-chip, micropatterned co-culture (MPCC), and organoids models. (G) Corresponding applications of 3D hepatic models derived by various cell types. Developed diseased or healthy 3D models are promising in the areas of hepatotoxin screening, idiosyncratic drug reaction study, diverse disease modeling, and hepatocyte transplantation.

\section{CELL TYPE DIVERSITY IN HUMAN LIVER}

\section{Cellular Composition of the Liver}

The liver has two main lobes, and both are made up of eight segments, supplied by two distinct blood sources: oxygenated blood from the hepatic artery and nutrient-rich blood from the hepatic portal vein (Figure 1A). From microscopic anatomy, the segments are composed of a thousand hexagonal hepatic lobules, possessing a unique structure and function. The hepatic lobules consist of portal triads (i.e., portal vein, bile duct, and hepatic artery) and surrounding hepatocytes arranged in linear cords radiating out a central vein (Figure 1B). As parenchymal cells, hepatocytes are responsible for major hepatic functions, including carbohydrate and lipid metabolism, detoxification, protein synthesis, and self-replication. Besides, resulting from the change of oxygen, nutrients, and signaling cues' gradient along with the portal triad, hepatocytes are of highly heterogeneity, presenting spatial zonation across the hepatic lobule (Pek et al., 2021). Different subpopulations of hepatocytes show a distinct number of chromosomes, expression profiles of RNA and proteins, and metabolic roles, which are relevant to the gradient of signaling proteins, oxygen, and nutrient supply from the portal to the central zone (Kietzmann, 2019). Additionally, diverse hepatic nonparenchymal cells are significant in maintaining the hepatic structure and function as well (Figure 1C). Among them, hepatic stromal cells are hepatic stellate cells (HSCs) involved in extracellular matrix biosynthesis upon liver injury and liver sinusoidal endothelial cells (LSECs) that form the fenestrated lining of the hepatic sinusoid. Other non-parenchymal cells 
include resident macrophages: Kupffer cells (KCs), $\mathrm{T}$ cells, and dendritic cells, and they all contribute to immune defense (Nuciforo and Heim, 2021). These non-parenchymal cells are appealing to be applied in the establishment of a 3D human hepatic model together with hepatic cell types, since the underlying mechanisms of hepatotoxicity and hepatic diseases involve interaction with these cells. Non-parenchymal cells support the microenvironment for maintenance of hepatic cell function and proliferation as well (Takebe et al., 2013; Ardalani et al., 2019).

\section{Parenchymal Hepatic Cell Types Used in In Vitro 3D Model}

Based on the knowledge of cellular composition and function of the liver, parenchymal hepatic cell types to be used in human hepatic 3D models can be obtained from healthy hepatic tissue, hepatocellular carcinoma, induced somatic cells, and human embryos (Figure 1D). After in vitro maintenance or differentiation, primary human hepatocytes, human hepatic cancer cell lines (HepG2, Huh-7, and HepaRG cell lines), human adult stem cell-derived HLCs (hASC-HLCs), and human pluripotent stem cell-derived HLCs (hESC-HLCs and hiPSC-HLCs) will be applied in the establishment of spheroid, liver-on-a-chip, MPCC, and organoid models with a range of advanced 3D culture techniques (Figures 1E,F). These models are promising in research areas of drug development, liver disease modeling, and hepatocyte transplantation (Figure 1G).

\section{Primary Human Hepatocytes}

Obtained from digesting human hepatic parenchyma (Figure 1D), the primary human hepatocyte (PHH) has been considered the golden standard cell type used in the hepatotoxicity study owing to its in vivo-like expression of DMETs (Gómez-Lechón et al., 2014). The PHH spheroid model expresses increased activity of phase I metabolism enzymes, including CYP3A4, CYP2C9, CYP2C8, CYP1A2, CYP2D6, CYP2B6, and CYP2C19, in comparison with HepG2 and HepaRG spheroid models, and maintains CYP1A1, CYP2D6, and CYP3A4 activities for at least 35 days (Bell et al., 2016; Berger et al., 2016; Vorrink et al., 2017). Also, the PHH obtained from the patient's sample can retain patient-specific expression of drug metabolizing enzymes and transporters for investigating patientspecific toxicities (Cox et al., 2020). However, the number and breadth of PHHs are limited by donor availability and invasive procedure to source. Though commercial $\mathrm{PHHs}$ have been provided by some companies, variability between batches has been well-recognized.

Previously, maintaining hepatic function and promoting propagation were main challenges to apply PHHs in establishing functional in vitro models. Freshly isolated PHHs undergo rapid dedifferentiation with decreased DMET expression and show low expansion capacity when cultured in 2D models (Rowe et al., 2013; Lauschke et al., 2016). This dedifferentiation was linked with reduced activity for transcription factors involved in hepatocyte differentiation, such as hepatocyte nuclear factors $4 \mathrm{a}$ and 1a (Oliva-Vilarnau et al., 2020). It was demonstrated that PHHs need unique culture conditions to propagate and maintain mature function in vitro. Exogenous supplements need to be added to facilitate the expansion, such as the epidermal growth factor (EGF), tumor necrosis factor (TNF), hepatocyte growth factor (HGF), WNT agonist, and transforming growth factor $\beta$ (TGF- $\beta$ ) inhibitor ( $\mathrm{Hu}$ et al., 2018; Xiang et al., 2019). 3D culture paradigms also provide a platform for ECM-cell interactions and cell-cell interactions which help maintain the mature hepatocyte phenotype (OlivaVilarnau et al., 2020).

\section{Human Hepatic Cancer Cell Lines: HepG2, Huh-7, and HepaRG}

Human hepatic cancer cell lines are obtained from human hepatocellular carcinoma (HCC) (Figure 1B). Compared with healthy in vivo hepatocytes or PHHs, tumor cell lines were thought to possess a different expression of DMETs due to unique epigenetic regulation and thus may be more suitable for establishing a cancer model instead of the drug screening model (Ingelman-Sundberg et al., 2013; Peng and Zhong, 2015; Nwosu et al., 2018). However, when compared with PHHs, cancer cell lines are superior in unlimited sources, reproducibility, batch-to-batch consistency, and cost-saving.

Commonly used hepatic cancer cell lines include HepG2, Huh-7, and HepaRG cell lines. Similar to the intra-tumor heterogeneity of HCC, the cell lines obtained from different parts or stages of tumor possess distinct cellular phenotypes and metabolic activities as well. HepG2 and Huh-7 were derived from well-differentiated human HCC that still possesses epithelial features and represents HCC in the early stage. HepG2 cells have been shown to maintain secretion of alpha1 antitrypsin (A1AT), albumin, $\alpha-1$-acid glycoprotein, alphafetoprotein, transferrin, fibrinogen, and plasminogen, though they closely resemble fetal hepatocytes instead of adult hepatocytes (Rowe et al., 2013; Cox et al., 2020). Compared with the Huh-7 cell line, the HepG2 cell line possesses wild-type $p 53$, lower chromosome numbers, and lower proliferation (41-57 h versus $23-27 \mathrm{~h}$ doubling time), exhibiting human epigenetic chromatin modification enzymes like PHHs (Nwosu et al., 2018; Ruoß et al., 2019; Rodríguez-Hernández et al., 2020).

HepaRG is the bipotent progenitor cell line derived from a chronic hepatitis C-related HCC (Gripon et al., 2002), possessing relatively slow mitotic activities $(48-69 \mathrm{~h})$. Interestingly, HepaRG cell lines can be differentiated to a mixture of hepatocyte islands and cholangiocyte-like cells upon exposure to dimethylsulfoxide (DMSO) or forskolin. The stable expression of CYP3A4, CYP1A2, drug transporters, and transcription factors was noted in differentiated HepaRG cells after treatment with DMSO (Aninat et al., 2006; Andersson et al., 2012; Rubin et al., 2015; Mayati et al., 2018). In 2D monolayer culture, HepaRG shows a higher expression of key DMETs more closely resembling PHHs as compared to HepG2 cell lines (SisonYoung et al., 2015). However, due to the longer time required for expansion and differentiation, HepaRG was less incorporated into high-throughput analyses (Cox et al., 2020). 


\section{Human Stem Cell-Derived Hepatocyte-Like Cells: Human Adult Stem Cell-Derived Hepatocyte-Like Cells, Human Induced Pluripotent Stem Cell-Derived Hepatocyte-Like Cells, and Human Embryonic Stem Cell-Derived Hepatocyte-Like Cells}

Human stem cell-derived hepatocyte-like cells (HLCs) can be induced from either liver tissue-resident human adult stem cells (hASCs) or pluripotent stem cells, hESCs and hiPSCs. Stem cells are capable of self-renewing and differentiating into multiple lineages. Hence, they provide unlimited sources to generate patient-specific HLCs, which exhibit mature hepatic function under special culture conditions (Calabrese et al., 2019; Carpentier et al., 2014; Huch et al., 2015; Huch and Koo, 2015; Takayama et al., 2012).

Reported hepatic hASCs are $\operatorname{LgrS}^{+}$(leucine-rich repeat-containing G-protein-coupled receptor $5^{+}$) and $\mathrm{EpCAM}^{+}$(epithelial cell adhesion molecule-expressing ${ }^{+}$) liver progenitor cells, and they can be obtained from the patients' liver tissue sample. The Lgr5 gene has been taken as a marker of E9.5-E10.0 bipotent liver progenitors residing at the apex of a liver hepatoblast hierarchy, and upon liver damage, Lgr 5 becomes highly upregulated in a subset of cells, contributing to the regeneration of the tissue (Huch et al., 2015; Prior et al., 2019). Epithelial cell adhesion molecule-expressing $\left(\mathrm{EpCAM}^{+}\right)$ cells also display characteristics of liver progenitors (i.e., selfrenewal and bipotency) as proven by clonogenic and differentiation assays (Schmelzer et al., 2007; Dorrell et al., 2014; Tarlow et al., 2014). To date, hESCs can be obtained either from embryos at morula and blastocyst stages or purchasing commercial cell lines including commonly used HSF6, HUES7, and H9 hESCs, while hiPSCs can be induced through reprogramming diverse human somatic cell types including liver tissue. Compared to hESCs, hiPSCs are available resources and maintain the patient's specific genetic changes, which benefits personalized treatment. Skin fibroblasts are the most recommended to use since they are easily isolated from skin biopsies (Takahashi and Yamanaka, 2006).

To generate hiPSCs, reprogramming factors can be integrated into somatic cell genomes via single-cassette vectors (Cre-Lox), mRNA or miRNA transfection, episomal plasmids, or non-integrating viral vectors (Takahashi et al., 2007; Raab et al., 2014; Ramboer et al., 2015; Mitani et al., 2017; Ang et al., 2018; Dao Thi et al., 2020). Furthermore, to characterize derived hESCs and hiPSCs, the expression of stage-specific embryonic antigen 4 (SSEA-4) and transcription factors OCT-3/4 and NANOG has been identified to verify the pluripotency (Allegrucci and Young, 2007; Carpentier et al., 2014). The idea of inducing hASCs, hESCs, and hiPSCs into HLCs is based on the natural development of the liver, when pluripotent epiblast cells sequentially turn into primitive streak, definitive endoderm, posterior foregut endoderm, embryonic liver progenitors, and hepatocytes under a series of stimulations (Ang et al., 2018; Ober and Lemaigre, 2018; Prior et al., 2019). To generate human adult stem cell-derived hepatocyte-like cells (hASCHLCs), after liver biopsy, cell isolation, and selection, hASCs can be cultured with a combination of growth factors including
HGF, EGF, fibroblast growth factor (FGF), WNT agonist, TGF$\beta$, and Rspol to induce activated bipotent liver progenitors that are capable of self-organization. Furthermore, blockade of ductal fate by the NOTCH inhibitor, in combination with the TGF- $\beta$ signaling inhibitor, removal of Rspo1, and addition of dexamethasone and bone morphogenetic protein (BMP) are applied to facilitate the differentiation of bipotent liver progenitors toward hASC-HLCs (Lemaigre, 2009; Zong et al., 2009; Huch et al., 2015). hASC-HLCs have been proved with hepatic function such as cytochrome activity and albumin, A1AT, and bile acid production in vitro (Huch et al., 2015). Similarly, current protocols to differentiate hESCs and hiPSCs toward HLCs usually involve treatment with 1) activin A and/ or TGF- $\beta$ to obtain definitive endoderm cells; 2$)$ FGF-2 and BMP-4 to induce liver progenitors; and 3) HGF, oncostatin M (OSM), dexamethasone, and/or co-culture with other cell types to specify hepatocytes. Differentiated hESC-HLCs and hiPSCHLCs were proved to express hepatic cellular markers including tyrosine aminotransferase, A1AT, and CYP7A1 and exhibit hepatic functions such as inducible CYP450 activity, albumin secretion, urea synthesis, glycogen storage, and low-density lipoprotein (LDL) uptake (Cai et al., 2007; Carpentier et al., 2014; Touboul et al., 2010). Transcriptional changes and immunocytochemistry revealed that differentiated hESC-HLCs showed more similarity to pericentral rather than periportal hepatocytes by exhibiting a pericentral hepatocyte marker, glutamine synthase (Baxter et al., 2015).

In addition to separated induction and differentiation procedures illustrated above, induced HLCs can be generated using direct lineage reprogramming technology which converted human fibroblasts to functional hepatocytes through overexpression of lineage-specific transcription factors (Vierbuchen and Wernig, 2012; Du et al., 2014; Huang et al., 2014). It has been proposed that, during lineage reprogramming, one cell type can be converted directly to the final mature state of another cell type bypassing its intermediate states. Huang et al. reported the application of lentiviruses carrying human pioneer factor FOXA3, together with liver-enriched transcription factors HNF1A and HNF4A, successfully induced conversion from human fibroblasts into HLCs, which exhibited mature hepatic functions comparable to cryopreserved PHHs instead of hepatic progenitor cells, including CYP450 enzyme activities and biliary excretion of drug compounds. Further genome-wide expression profile analysis and gene set enrichment analysis indicated that human fibroblasts underwent hepatic conversion by transcriptional alterations at the whole-genome level. (Huang et al., 2014). Du et al. reported viral-mediated overexpression of transcription factors HNF1A, HNF4A, and HNF6 along with maturation factor PROX1 and liver-enriched transcription factors ATF5 and CEBPA successfully induced conversion from human fibroblasts into HLCs, which possessed metabolic activities of CYP3A4, CYP1A2, CYP2B6, CYP2C9, and CYP2C19 comparable to fresh PHHs.

Nevertheless, one should be cautious when considering the actual maturity of HLCs. Further maturation after differentiation of hiPSC/hESC-HLCs was proposed due to fetal-like hepatic characteristics of HLCs, such as drug 
TABLE 1 | Summary of characteristics of cell types used in human 3D hepatic models.

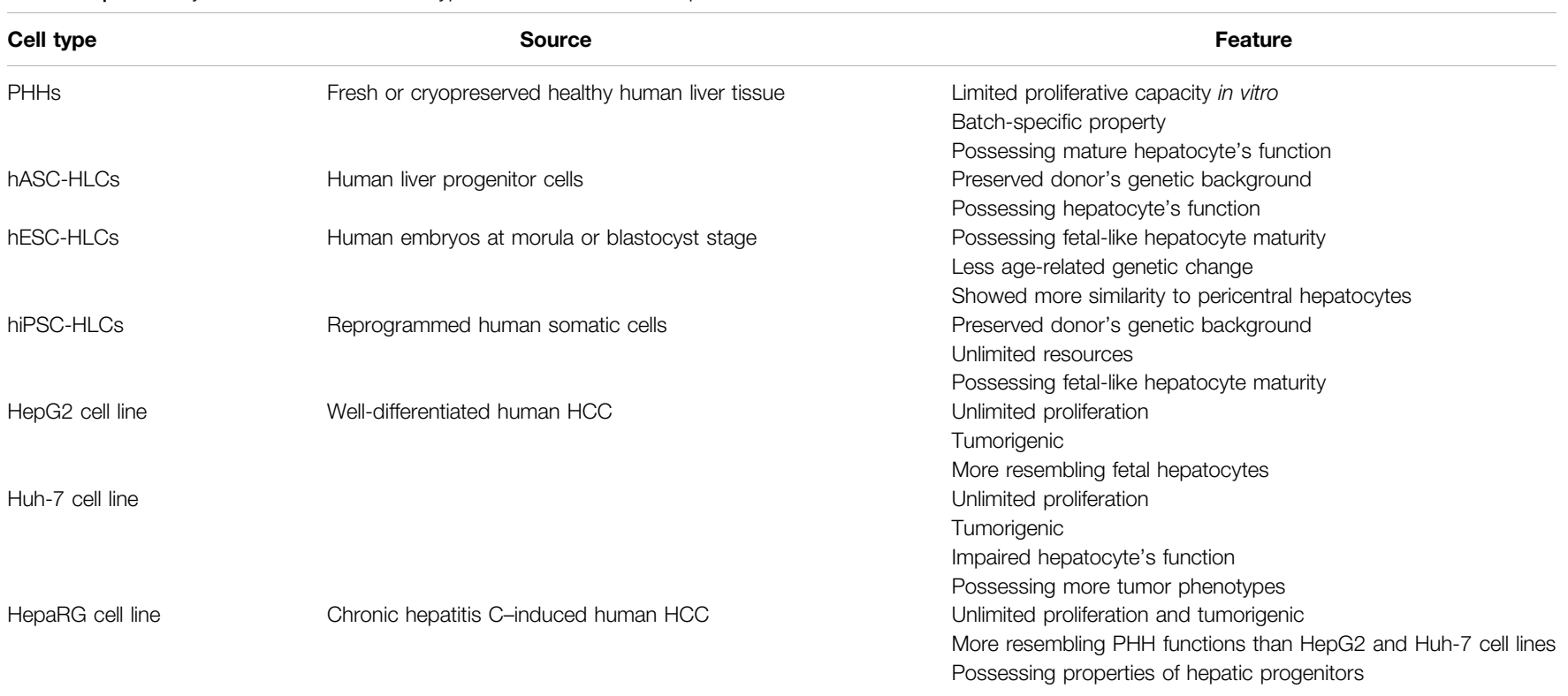

PHHs, primary human hepatocytes; hASCs, human adult stem cells; hiPSCs, human induced pluripotent stem cells; hESCs, human embryonic stem cells; HLCs, hepatocyte-like cells; HCC, hepatocellular carcinoma.

metabolism capacity, albumin secretion level, and urea secretion level, which are considered lower than those of fresh adult PHHs (Takayama et al., 2012; Baxter et al., 2015). The previous study indicated that the average and variance of CYP3A4 activity levels in $\mathrm{PHH}$-derived hiPSC-HLCs, non-PHH-derived hiPSCHLCs, and hESC-HLCs were similar to each other, but the CYP1A2, CYP2C9, and CYP3A4 activity levels in the PHHhiPSC-HLCs were estimated to be around $60 \%$ of those of their parental PHHs (Takayama et al., 2014). The albumin and urea secretion levels in HUES7 cell-derived hESC-HLCs were approximately 8-fold and 18-fold lower than those from fresh adult PHHs, respectively. Meanwhile, principal component analysis revealed that differentiated hESC-HLCs and hiPSC-HLCs possessed a high expression level of alphafetoprotein, glutathione S-transferase $\pi$, and heat shock protein 47 and a low level of CYP2A6 and ADH activity, which were comparable to those of fetal PHHs instead of adult PHHs (Rowe et al., 2013; Baxter et al., 2015). It has been suggested that the 3D culture technique with a natural or synthetic ECM support or cell-cell contact can promote the maturation of the hiPSC/ hESC-HLCs and maintenance of hepatic function. When compared with a monolayer culture model, these hiPSC/ hESC-HLCs' 3D model exhibited a higher expression level of hepatic-specific gene and superior capability in adult hepatic function (Nagamoto et al., 2012; Ramasamy et al., 2013; Takayama et al., 2013).

Collectively, the sources and divergent characteristics of the above three cell types are summarized in Table 1. These unique properties of cell types indicate their advantages in different research fields of in vitro $3 \mathrm{D}$ modeling paradigm as discussed in the below part.

\section{HEPATIC CELL TYPES AND CORRESPONDING APPLICATION WITH 3D CELL MODELS \\ Drug Development Hepatotoxin Screening to Avoid Drug-Induced Liver Injury}

A life-threatening adverse drug reaction, drug-induced liver injury (DILI), is accompanied by oxidative stress, metaboliteinduced hepatotoxicity, and activated innate and adaptive immune responses (Donato and Tolosa, 2021). Of the affected patients, $9.4 \%$ die or require liver transplantation and $18.9 \%$ show persistent liver damage 6 months after DILI diagnosis (Fontana et al., 2014). In addition to clinical importance, DILI is responsible for the most post-marketing withdrawals of drugs. In the last 30 years, 14 drugs have been withdrawn from the US and European markets due to hepatotoxicity shown in postmarketing stages, representing a financial burden for the pharmaceutical industry (Zhou et al., 2019). One of the reasons for high incidence of DILI is an unsuitable preclinical hepatotoxin screening and assessment model, as short-term 2D cell models usually lead to incompetent drug metabolism and restrict the predictivity of DILI. To fill this gap, more predictive in vitro models need to be developed for preclinical drug screening.

The current hepatic 3D model for DILI prediction mainly utilized PHH cell type (Table 2). Khetani et al. established the PHH MPCC model to evaluate the hepatotoxicity of 35 DILIpositive and 10 DILI-negative compounds listed by $\mathrm{Xu}$ and colleagues (Xu et al., 2008), along with albumin, urea, ATP, and glutathione (GSH) levels as the endpoints for DILI 
TABLE 2 | Selected hepatotoxin screening using 3D hepatic models established with different cell types.

\begin{tabular}{|c|c|c|c|c|}
\hline Cell type & Culture paradigm & $\begin{array}{l}\text { Drug exposure } \\
\text { period }\end{array}$ & Endpoints & References \\
\hline $\mathrm{PHHs}$ & MPCC co-culture & 9 days & $\begin{array}{l}\text { Albumin, urea, and glutathione levels and cellular ATP } \\
\text { content }\end{array}$ & Khetani et al. (2013) \\
\hline $\mathrm{PHHS}$ & Spheroid co-culture & 14 days & Cellular ATP content & Proctor et al. (2017) \\
\hline $\mathrm{PHHs}$ & $\begin{array}{l}\text { Spheroid mono- } \\
\text { culture }\end{array}$ & 14 days & Cellular ATP content & Li et al. (2020) \\
\hline $\mathrm{PHHs}$ & $\begin{array}{l}\text { Spheroid mono- } \\
\text { culture }\end{array}$ & 14 days & Cellular ATP content & Vorrink et al. (2018) \\
\hline $\mathrm{PHHs}$ & $\begin{array}{l}\text { Spheroid mono- } \\
\text { culture }\end{array}$ & 28 days & Cellular ATP content & Bell et al. (2016) \\
\hline $\mathrm{PHHs}$ & MPCC co-culture & 14 days & $\begin{array}{l}\text { Cell viability } \\
\text { Albumin secretion } \\
\text { Urea synthesis } \\
\text { CYP3A4 activity } \\
\text { Global gene expression profiles }\end{array}$ & Ware et al. (2017) \\
\hline HepG2 & $\begin{array}{l}\text { Spheroid mono- } \\
\text { culture }\end{array}$ & 6 days & $\begin{array}{l}\text { Oxidative stress response pathway } \\
\text { UPR pathway } \\
\text { DNA damage response pathway }\end{array}$ & Hiemstra et al. (2019) \\
\hline HepaRG & $\begin{array}{l}\text { Spheroid mono- } \\
\text { culture }\end{array}$ & 6 days & Cellular ATP content & $\begin{array}{l}\text { Ramaiahgari et al. } \\
(2017)\end{array}$ \\
\hline HepaRG & $\begin{array}{l}\text { Spheroid mono- } \\
\text { culture }\end{array}$ & 7 days & $\begin{array}{l}\text { Cellular ATP content } \\
\text { CYP1A and CYP3A4 activity }\end{array}$ & Ott et al. (2017) \\
\hline $\begin{array}{l}\text { hiPSC-HLCs; hESC-HLCs; } \\
\text { HepG2 }\end{array}$ & $\begin{array}{l}\text { Spheroid mono- } \\
\text { culture }\end{array}$ & $24 \mathrm{~h}$ & Cell viability & Takayama et al. (2013) \\
\hline hiPSC-HLCs; hESC-HLCs & $\begin{array}{l}\text { Organoid mono- } \\
\text { lineage }\end{array}$ & $72 \mathrm{~h}$ & $\begin{array}{l}\text { Cell viability } \\
\text { Cholestatic function } \\
\text { Mitochondrial toxicity }\end{array}$ & Shinozawa et al. (2021) \\
\hline
\end{tabular}

PHHs, primary human hepatocytes; MPCC, micropatterned co-culture; hESCs, human embryonic stem cells; hiPSCs, human induced pluripotent stem cells; HLCs, hepatocyte-like cells.

identification. Upon four repeated dosages over the time course of 9 days, the MPCC model correctly predicted 23 out of 35 DILIpositive compounds ( $65.7 \%$ sensitivity) with one out of ten falsepositive compounds (90\% specificity) (Khetani et al., 2013). For chronic hepatotoxicity assays, Bell and colleagues proved that preserved hepatic phenotypes and long-term functionality in the PHH spheroid models allowed them to be applied. They dosed PHH spheroids every 2 days with five hepatotoxins: amiodarone, bosentan, diclofenac, fialuridine, and tolcapone, and determined the cell viability via detecting cellular ATP content after $48 \mathrm{~h}$ and 8 and 28 days. Significant reduction in the $\mathrm{EC}_{50}$ values for all tested compounds was observed between $48 \mathrm{~h}$ and 8 days, reflecting toxicity in vitro at clinically relevant concentrations. Long-term cytotoxicity was most prominent for fialuridine, for which cytotoxicity was detected as $0.1 \mu \mathrm{M}$ at 28 days compared with $\mathrm{EC}_{50}>100 \mu \mathrm{M}$ at $48 \mathrm{~h}$, highlighting the essential role of the $\mathrm{PHH} 3 \mathrm{D}$ culture model in long-term hepatocytotoxicity screening (Bell et al., 2016). Meanwhile, three larger panels of hepatotoxicity studies have been conducted in $\mathrm{PHH}$ spheroids to date with ATP quantifications as the single endpoint (Proctor et al., 2017; Vorrink et al., 2018; Li et al., 2020). Proctor et al. used high-throughput 3D InSight $^{\mathrm{TM}}$ Human Liver Microtissues spheroid models co-culturing $\mathrm{PHH}, \mathrm{KCs}$, and LSECs to test the hepatotoxicity of 110 drugs (69 DILI-positive and 41 DILInegative). $\mathrm{PHH}$ co-culture spheroids after a 14-day repeated exposure predicted DILI with $19-61 \%$ sensitivity and $81-98 \%$ specificity, depending on thresholds employed (Proctor et al., 2017). In contrast, $\mathrm{Li}$ et al. established $\mathrm{PHH}$ mono-culture spheroids to test the hepatotoxicity of 100 drugs (62 DILIpositive and 38 DILI-negative). Upon 14 days of repeated exposure, the model reported prediction of DILI with $32-61 \%$ sensitivity and 79-95\% specificity, depending on thresholds employed ( $\mathrm{Li}$ et al., 2020). Interestingly, though for above $\mathrm{PHH}$-derived models, whether co-culture with nonparenchymal cells or not seems to not significantly affect the differentiation between DILI-positive and -negative drugs, KCs were proved to potentiate the cytotoxicity induced by trovafloxacin and acetaminophen in $\mathrm{PHH} / \mathrm{KC}$ co-culture spheroids, manifested as a lower $\mathrm{IC}_{50}$ value when compared with $\mathrm{PHH}$ mono-culture. However, a protective role of activated KCs in co-culture compared to mono-culture was shown if co-treated with acetaminophen and lipopolysaccharides. Additional tests with 14 DILI-positive compounds comparing mono-culture and co-culture spheroids indicated that KCs exerted compound-dependent differential effects on drug-induced cytotoxicity (Li et al., 2020). Vorrink and colleagues got better screening outcomes with higher sensitivity via establishing $\mathrm{PHH}$ mono-culture spheroids in specific chemically defined conditions which were demonstrated to retain $\mathrm{PHH}$ viability, functionality, and transcriptomic, proteomic, and metabolomic phenotypes for multiple weeks (Bell et al., 2016; Bell et al., 2017; Vorrink et al., 2017). Upon repeated exposure to 123 drugs (70 DILIpositive and 53 DILI-negative) for 14 days, $\mathrm{PHH}$ spheroids predicted the hepatotoxicity of 48 out of 70 compounds (sensitivity $=69 \%$ ), and no false-positive result was reported 
(specificity $=100 \%$ ). Furthermore, this model correctly distinguished five pairs of DILI-positive drugs (amodiaquine, troglitazone, clozapine, nefazodone, and bosentan) and their DILI-negative structural analogs (primaquine, rosiglitazone, amoxapine, buspirone, and ambrisentan), underlining the potential of $\mathrm{PHH}$-derived $3 \mathrm{D}$ models in evaluating drug candidates at chemical derivatization stages during drug development (Vorrink et al., 2018).

Nevertheless, merely adopting functional endpoints as parameters failed to elucidate detailed mechanistic insights into diverse pathways involved in liver hepatotoxicity. Instead, global gene expression profiling has the potential to reveal the mechanism of action of hepatotoxins by identifying genes that are candidate biomarkers of adverse drug effects. Meanwhile, it seems more sensitive in hepatotoxic identification than conventional cellular functional endpoints (Barros and Martin, 2008; Ware et al., 2017). Ware and colleagues established PHH MPCC models and confirmed global gene expression patterns in these models can be used to distinguish hepatotoxic drugs (troglitazone, nefazodone, ibufenac, and tolcapone) from their non-toxic analogs (rosiglitazone, buspirone, ibuprofen, and entacapone). They treated MPCC models with pair drugs at their respective non-toxic Cmax for 1, 7, and 14 days and then assessed the functional endpoints (cell viability, albumin secretion, urea synthesis, and CYP3A4 activity) and global gene expression profiles via Affymetrix whole genome human microarrays at each time point. Interestingly, at a non-toxic dose of both toxins and non-toxins, $\mathrm{PHH}$ viability, hepatic urea secretion, and albumin level were not significantly affected over 2 weeks, while different transcript perturbations involved in KEGG pathways and GO processes were noted with time change, suggesting that hepatotoxins led to a greater number of differentially expressed transcripts than corresponding nontoxic analogs (Ware et al., 2017). Except for gene expression profiling, cellular labeling technique inserting exogenous reporter genes into hepatic cell genomes can be combined with a $3 \mathrm{D}$ culture paradigm to monitor DILI-relative pathways such as oxidative stress response pathways, unfolded protein response pathway, and DNA damage response pathway, so as to explore the drug-specific DILI mechanism (Wink et al., 2018; Hiemstra et al., 2019). Hiemstra et al. established spheroid models by using six HepG2-GFP cellular stress reporter cell lines representing Nrf2 activation (Srxn1-GFP and NQO1-GFP), unfolded protein response (BiP-GFP and Chop-GFP), and DNA damage response (p21-GFP and Btg2-GFP). Upon 6 days of daily repeated exposure with 33 compounds (20 most-DILI-concern drugs, 7 less-DILI-concern drugs, and 6 no-DILI-concern drugs), strongest stress response activation was observed at the sixth day in HepG2-GFP spheroids, with the BiP and Srxn1 pathways being most responsive for most-DILI-concern compounds, indicating cellular stress reporter cell line-derived spheroid models were promising for mechanism-based identification of compounds with liability for DILI (Hiemstra et al., 2019).

Except for PHH cell type, HepaRG cell type was also used in some small panels of drug testing. Ramaiahgari et al. established the HepaRG spheroid with retained functionality for 28 days. Upon repeated exposure to two pairs of hepatotoxins (trovafloxacin, troglitazone) and non-toxic analogs (levofloxacin, rosiglitazone) for 6 days, dose-dependent cytotoxicity with hepatotoxins compared with their non-toxic analogs was observed in HepaRG spheroids. Besides, the model correctly identified DILI-positive compounds: acetaminophen, diclofenac, isoniazid, and cyclosporine A (Ramaiahgari et al., 2017). Similarly, Ott et al. developed HepaRG spheroids along with multiple cellular functional endpoints. Upon repeatedly exposing spheroids to 10 hepatotoxins and 2 non-toxins for 7 days, the model correctly flagged $7 / 10$ compounds as hepatotoxins with $100 \%$ specificity (Ott et al., 2017).

However, sensitivity of HepG2 and HepaRG cell types to hepatotoxins was still considerably lower than that in $\mathrm{PHH}$ models which had been seen as the gold standard cell type for predicting human hepatotoxic drugs (Gómez-Lechón et al., 2014; Hendriks et al., 2016; Zhou et al., 2019). Hendriks et al. compared the sensitivity of $\mathrm{PHH}$ spheroids and HepaG2 spheroids to acetaminophen- and tetracycline-induced hepatotoxicity along with albumin secretion as the endpoint. Upon 8 days of repeated exposure, the PHH spheroid exhibited a lower $\mathrm{TC}_{50}(1.3 \mathrm{mM})$ than the HepaRG spheroid $(1.8 \mathrm{mM})$ of acetaminophen and lower $\mathrm{TC}_{50}(0.1 \mathrm{mM})$ than the HepaRG spheroid $(0.2 \mathrm{mM})$ of tetracycline (Hendriks et al., 2016). Furthermore, Zhou et al. comparatively reviewed the sensitivity of current hepatic 3D models to acetaminophen-induced hepatotoxicity. Under the same drug exposure and mono-culture condition, the $\mathrm{PHH}$ derived spheroid exhibited a lower $\mathrm{TC}_{50}$ than the HepaRG spheroid, while the HepaRG spheroid exhibited a lower $\mathrm{TC}_{50}$ than the hiPSC-HLC spheroid and HepG2 spheroid (Zhou et al., 2019). Though this comparison only focused on the spheroid model and acetaminophen-induced hepatotoxicity, it confirmed the superior $\mathrm{PHH}$ cell type in hepatotoxicity studies, which has been proved from the perspective of genetic profiling and expression as well. In spheroids, $\mathrm{PHH}$ showed that proteomic signatures closely resemble the human liver in vivo and retained their transcriptomic and metabolomic profiles for multiple weeks (Bell et al., 2016; Bell et al., 2017; Vorrink et al., 2017; Bell et al., 2018). In contrast, transcriptomic patterns of other cell types differed substantially. 8,148 out of 17,462 genes analyzed were differentially expressed in $\mathrm{PHH}$ spheroids compared to HepaRG cells (Bell et al., 2017).

For DILI study using stem cell-derived hepatocyte-like cells, Takayama et al. established hiPSC-HLCs spheroids to compare their susceptibility toward drug-induced hepatotoxicity with that of HepG2 spheroids. hiPSC-HLC spheroids showed higher susceptibility along with less cell viability in the treatment with 19/22 hepatotoxins for $24 \mathrm{~h}$. Meanwhile, hepatotoxins caused cell death in hiPSC-HLC spheroids, which was partially rescued by treatment with CYP inhibitors, suggesting that hiPSCHLC spheroids are promising in screening toxicity of the reactive metabolites that were metabolized by CYP enzymes. Additionally, they also compared the maturation of hepatic function between monolayer models and spheroid models. When compared with hESC-HLC mono-culture, hESC-HLC spheroids showed a higher gene expression level of albumin, CYP enzymes, conjugation enzymes, hepatic transporters, hepatic nuclear receptors, hepatic transcription factors, and 
bile canalicular transporters. The ability of bile acid uptake and efflux and secretion level of albumin and urea in the spheroid model were also superior to those in the monolayer model. When compared with the hiPSC-HLC monolayer culture model, hiPSCHLC spheroids exhibited higher CYP induction potency and CYP2C9 and CYP3A4 activity levels after treatment with rifampicin for $48 \mathrm{~h}$ (Takayama et al., 2013). Moreover, Shinozawa and colleagues developed the hiPSC/hESC-HLC organoid model with bile transport function, which allowed for measurement of cell viability and cholestatic and mitochondrial toxicity (Shinozawa et al., 2021). Upon exposure to 238 marketed drugs, the model reported $88.7 \%$ sensitivity and $88.9 \%$ specificity, which provided values comparable to or higher than those in previous studies with PHH models (Xu et al., 2008; Khetani et al., 2013; Proctor et al., 2017; Vorrink et al., 2018). With proved bile transport function, this model supported mechanism classification of DILI, including cholestatic toxicity, mitochondrial toxicity, bile salt export pump deficit, or further unknown vulnerable mechanism. Different from the simplified culture model without hepatic canaliculi structure, organoid models established with directed hiPSCs/ hESCs formed the unidirectional bile acid transport pathway, which faithfully mimicked the metabolite excretion into bile canaliculi in vivo. Meanwhile, compared with the reported $\mathrm{PHH}$ sandwich culture, it is believed the pluripotent stem cell resource could solve reproducibility and high-throughput challenges (Shinozawa et al., 2021).

Taken together, it has been suggested that repeated exposure for at least 6 days came with higher sensitivity in comparison with 24 or $48 \mathrm{~h}$ single exposure (Ramaiahgari et al., 2014; Ott et al., 2017; Proctor et al., 2017; Ramaiahgari et al., 2017; Hiemstra et al., 2019; Li et al., 2020). And though there are diverse measuring approaches for detecting DILI-relevant cytotoxicity, taking the cellular ATP level as the single endpoint was sufficient for distinguishing between hepatotoxins and non-toxins, which fits the large screening needs of early drug discovery and compound structure design based on structural toxicity (Shah et al., 2015). Though the PHH model is still a mainstream screening platform with superior maturation of hepatic function, 3D culture models which support ECM formation and cell-cell contact can promote further maturation of stem cell-derived HLCs. hESC/hiPSC-HLC 3D models, especially organoid models, have shown comparable predictive power and unique advantages in imitating in vivo tissue-like structures and cellular composition, including bile canaliculi, zone-specific architecture, hepatic mesenchyme, endothelial cells, and cholangiocytes (Shinozawa et al., 2021). Therefore, they are promising in cholestatic, hepatocellular, or further unknown complex DILI mechanism studies. It is believed that stem cell-derived HLCs would serve as an alternative hepatotoxin screening platform and overcome current resource shortage and reproduction challenge when using $\mathrm{PHHs}$.

\section{Idiosyncratic Drug Reaction}

Except for routine hepatotoxicity screening to avoid DILI for most patients, the idiosyncratic drug reaction study focusing on the influence of genetic polymorphisms is significant for clinical prescription as well. Although the most DILI-related acute liver failure was dose-dependent, roughly $10-15 \%$ of it can be attributed to individual effects instead of dose-caused effects (Reuben et al., 2010). Genetic polymorphism, especially singlenucleotide polymorphism (SNP), is related to interindividual differences in CYP metabolism capacity and immune-mediated drug responsiveness (Ingelman-Sundberg, 2001; Gerussi et al., 2021). Current approaches for idiosyncratic drug response are relatively limited since routine hepatotoxicity screening mostly relies on $\mathrm{PHH}$ cell type obtained from healthy livers with fully functional DMETs, which may not be able to reveal the risk of genetic polymorphisms. Thus, cell systems with corresponding defects and a novel strategy to reveal the relationship of genotype and idiosyncratic drug reaction are needed (Chalasani and Björnsson, 2010; Urban et al., 2014; Roth and Lee, 2017). The establishment of human hepatic 3D models with genetic and phenotypic variability in pharmacokinetics provides insight into the pathogenesis of idiosyncratic drug effects.

Among various CYPs expressed in the liver, CYP2D6 handles a quarter of commercially used drugs and has been proved with diverse phenotypic variability owing to single-nucleotide polymorphism (SNP) (S. F. Zhou, 2009). Vorrink and colleagues utilized patients' $\mathrm{PHH}$ spheroids to evaluate the impact of genetic polymorphism on the metabolic fate of dextromethorphan. In vivo, dextromethorphan is primarily metabolized to dextrorphan by CYP2D6; in case of CYP2D6 deficit, it can be metabolized to 3-methoxymorphinan by CYP3A4. In this study, $\mathrm{PHH}$ spheroids with genotypically defined extensive $\left(C Y P 2 D 6{ }^{*} 1 /{ }^{*} 1\right.$ and $\left.C Y P 2 D 6{ }^{*} 1 /{ }^{\star} 4\right)$ and poor $\left(C Y P 2 D 6{ }^{*} /{ }^{*} 10\right)$ CYP2D6 enzymes were exposed to dextromethorphan. The poor metabolizer showed shunted metabolic flux toward CYP3A4-dependent metabolism, resulting in the predominant formation of 3methoxymorphinan (Vorrink et al., 2017). This outcome was consistent with in vivo dextromethorphan metabolism, suggesting that genetic polymorphism-related drug response can be presented in PHH spheroids (Vorrink et al., 2017). In addition to $\mathrm{PHH}$ models, in vitro models established with pluripotent stem cells (HLCs) from different donors are promising for exploring individual susceptibility as well. Importantly, hiPSCs can be reprogrammed from different somatic cell types and are highly reproducible, which solves the challenge of $\mathrm{PHH}$ shortage. To prove that the variable genetic background is also retained in the derived HLCs, Takayama et al. generated HLCs from 12 donors' PHHs with various SNPs on CYP2D6. By comparing PHH-hiPSC-HLCs and parental PHHs in CYP2D6 enzyme metabolism capacity, expression of CYP genes and expression of SNPs on CYP genes, and responses to 72-h treatment with CYP2D6activated drug tamoxifen and responses to 24-h treatment with CYP2D6-detoxified drug desipramine and perhexiline, they proved that interindividual differences in CYP2D6mediated metabolism and hepatotoxicity due to SNPs in CYP2D6 were reproduced in the PHH-hiPSC-HLCs (Takayama et al., 2014). Therefore, CYP2D6 polymorphism-mediated drug-induced hepatotoxicity could also be predicted in hiPSC-HLC culture models. The CYP 
variant $\mathrm{CYP}^{2} \mathrm{C}^{*} 2$ is also known for encoding proteins with reduced enzymatic activity in comparison with wild-type CYP2C9 ${ }^{\star} 1$ (Rettie et al., 1994). Shinozawa et al. established an hiPSC-HLC organoid model from eight donors with $C Y P 2 C 9^{\star} 2$ enzyme activity as normal $(C / C)$ or intermediate $(C / T)$ to study genomic predisposition to bosentan-induced cholestasis. They found that, in $C / T$ allele carrier organoids, the excretion of fluorescent bile acid into organoids was severely impaired by bosentan (positive rate: $C / C, 17.1 \%$ positive; $C / T, 70.8 \%$ positive) (Shinozawa et al., 2021). This result was in accordance with the CYP2C $9{ }^{\star 2}$ polymorphism-related bosentan-induced DILI study in patients (Markova et al., 2013).

The idiosyncratic drug reaction screening research can be independent of identifying CYP polymorphism. For instance, the hiPSC-HLC organoid model was applied to support the DILIrelated genome-wide association study (GWAS) and underlying DILI-vulnerable pathway identification. Koido and colleagues established PHH 2D models and hiPSC-HLC organoid models to assess the DILI-predictive power of polygenic risk score (PRS). In this study, whole-genome genotypes of PHHs and hiPSCHLCs from different healthy donors were determined by an SNP array to calculate their PRSs based on the previous GWAS. Upon exposure of 12 hepatotoxic drugs, the PRS-dependent cytotoxic trend across multiple drugs was noted in both $\mathrm{PHH} 2 \mathrm{D}$ models and hiPSC-HLC organoid models, revealing a shared DILI predisposition which was correlated with polygenic scores but independent of properties of each specific drug. In addition, transcriptome analysis of hiPSC-HLC organoid models proved that expression levels of mitochondrial toxicity-related genes and unfolded protein response-related genes were correlated with the PRS (Koido et al., 2020). Similarly, hASC-HLCs also maintain interindividual variability in drug response and can be adopted as an initial screening platform for an idiosyncratic drug event. Wang et al. (2010) established hASC-HLC spheroids from six donors to reveal idiosyncratic events of eight tyrosine kinase inhibitors (TKIs): erlotinib, lapatinib, cabozantinib, foretinib, gefitinib, crizotinib, ceritinib, and tepotinib. Dose-dependent toxicity curves obtained in these spheroids were significantly different upon 48-h treatment of four drugs: erlotinib $\left(\mathrm{TC}_{50}\right.$ ranged from non-detected to $24.05 \pm 10.9 \mu \mathrm{M})$, lapatinib $\left(\mathrm{TC}_{50}\right.$ ranged from non-detected to $\left.65.1 \pm 56.6 \mu \mathrm{M}\right)$, cabozantinib $\left(\mathrm{TC}_{50}\right.$ ranged from non-detected to $36.3 \pm$ $11.9 \mu \mathrm{M}$ ), and foretinib $\left(\mathrm{TC}_{50}\right.$ value ranged from non-detected to $130.5 \pm 43.4 \mu \mathrm{M}$ ), suggesting that heterogeneity influenced the toxicity of these four TKIs, while the other four TKIs showed strong toxicity to all spheroids derived from different donors, indicating that their cytotoxicity effects were less affected by individual heterogeneity (Wang et al., 2019).

Collectively, genetic polymorphism-relevant interindividual differences in drug responses were proved to be retained in $\mathrm{PHH}$, hASC-HLC, and hiPSC-HLC culture models, enabling preclinical idiosyncratic drug response screening (Koido et al., 2020; Shinozawa et al., 2021; Takayama et al., 2014; Vorrink et al., 2017; Wang et al., 2019). Particularly, establishing the hiPSCHLC biobank and applying them in idiosyncratic drug event screening is a promising strategy to overcome the shortage of $\mathrm{PHH}$ resources and fully reveal interindividual variations in drug response due to genetic makeup. In the future, dosing these cell types with drugs under different diseased backgrounds such as HBV infection, NAFLD, and HCC should also provide clues to patient-specific drug adverse responses (Lin and Khetani, 2016). Meanwhile, as mentioned above, the idiosyncratic drug reaction research can be independent of identifying CYP polymorphism. Several ongoing research studies have revealed the significance of immunogenetic in idiosyncratic drug response (Gerussi et al., 2021); in the context of this condition, genome-wide analysis and relevant statistic models would provide a new prospective in addition to merely focusing on DMET-related candidate genes, and both PHHs and hiPSC-HLCs are compatible with this technique (Koido et al., 2020).

\section{Liver Disease Modeling Non-Alcoholic Fatty Liver Disease}

Non-alcoholic fatty liver disease (NAFLD) encompasses a series of hepatic parenchymal damage with varying degrees, ranging from simple fat accumulation and non-alcoholic steatohepatitis (NASH) with subsequent inflammation and necrosis, to hepatic fibrosis, cirrhosis, and even HCC. NAFLD typically develops in patients with the metabolic syndrome or ectopic lipid deposition-induced insulin resistance resulting from chronic energy surplus. Insulin resistance induces glucose conversion into adipose tissue in the liver via hepatic de novo lipogenesis and disrupts lipolysis, contributing to hepatic inflammation, oxidative stress accumulation, mitochondrial damage, and cell apoptosis (Thiagarajan et al., 2021). Among all disease stages, $\mathrm{NASH}$ is thought to be the turning point to the life-threatening stages, as HSCs differentiate into myofibroblast-like cells, which cause fibrosis and predispose patients to cirrhosis and hepatocellular carcinoma in NASH. However, no FDAapproved drug therapy for NASH exists currently, and the conservative treatment depends on lifestyle intervention and weight control, highlighting the need of pathogenesis study and exploration of new drug targets (Boeckmans et al., 2018). $3 \mathrm{D}$ cell models of NAFLD can be induced via exposure of appropriate cell types to pathophysiological culture conditions or NAFLD-inducer drugs. The physiologically healthy medium contained $5.5 \mathrm{mM}$ glucose and $0.1 \mathrm{nM}$ insulin, whereas pathologic media consisted of a high level of free fatty acid (FFA), insulin, and monosaccharides in line with the human in vivo NAFLD environment (Zhang et al., 2014). Based on current research, NAFLD models were mainly established with PHH cell type (Table 3 ).

Mono-cultured $\mathrm{PHH}$ spheroids and liver-on-a-chip models have been reported with successfully mimicked lipid accumulation, steatosis, insulin resistance, transcriptional change in relevant genes, and expression of inflammatory and fibrotic markers. Bell and colleagues demonstrated that steatosis was induced in $\mathrm{PHH}$ spheroids by exposure to probe drug cyclosporine $\mathrm{A}(30 \mu \mathrm{M})$ for $48 \mathrm{~h}$, indicating the $\mathrm{PHH}$ spheroid was a promising model of drug-induced steatosis (Figure 2A) (Bell et al., 2016). Kozyra and colleagues further illustrated that transcriptional change related to steatosis and insulin resistance can be induced in PHH spheroids with pathophysiological FFA, monosaccharides, and insulin. After 14 days of exposure, 
TABLE 3 | Selected 3D NAFLD models established from different cell types.

\begin{tabular}{|c|c|c|c|c|}
\hline Cell type & Culture paradigm & $\begin{array}{l}\text { Exposure } \\
\text { duration }\end{array}$ & Endpoints/outcomes & References \\
\hline $\mathrm{PHHs}$ & Spheroid mono-culture & $48 \mathrm{~h}$ & Hepatic lipid accumulation & Bell et al. (2016) \\
\hline $\mathrm{PHHs}$ & Spheroid mono-culture & 21 days & $\begin{array}{l}\text { Hepatic lipid accumulation } \\
\text { Transcriptional changes in genes associated with hepatic gluconeogenesis, } \\
\text { glycolysis, and lipogenesis }\end{array}$ & Kozyra et al. (2018) \\
\hline $\mathrm{PHHs}$ & $\begin{array}{l}\text { Liver-on-a-chip mono- } \\
\text { culture }\end{array}$ & 14 days & $\begin{array}{l}\text { Hepatic lipid accumulation } \\
\text { Transcriptional changes in genes associated with insulin resistance and lipid } \\
\text { metabolism } \\
\text { Increased inflammatory and fibrotic markers }\end{array}$ & $\begin{array}{l}\text { Kostrzewski et al. } \\
\text { (2017) }\end{array}$ \\
\hline $\mathrm{PHHs}$ & MPCC co-culture & 18 days & $\begin{array}{l}\text { Hepatic lipid accumulation } \\
\text { Decreased sensitivity to insulin-mediated inhibition of glucose output and } \\
\text { dysregulated insulin signaling }\end{array}$ & $\begin{array}{l}\text { Davidson et al. } \\
\text { (2016) }\end{array}$ \\
\hline $\mathrm{PHHs}$ & $\begin{array}{l}\text { Liver-on-a-chipco- } \\
\text { culture }\end{array}$ & 10 days & $\begin{array}{l}\text { Hepatic lipid accumulation } \\
\text { Decreased sensitivity to insulin-mediated inhibition of glucose output and } \\
\text { dysregulated insulin signaling } \\
\text { Increased oxidative stress and apoptosis } \\
\text { Increased inflammatory analyte secretion and fibrogenic activation markers }\end{array}$ & Feaver et al. (2016) \\
\hline HepG2 & $\begin{array}{l}\text { Gut-liver-on-a-chip co- } \\
\text { culture }\end{array}$ & $24 \mathrm{~h}$ & Accumulated chylomicrons in HepG2 & Lee \& Sung (2018) \\
\hline $\begin{array}{l}\text { hiPSC-HLCs; } \\
\text { hESC-HLCs }\end{array}$ & Organoid tri-lineage & 7 days & $\begin{array}{l}\text { Hepatic lipid accumulation } \\
\text { Increased inflammatory cytokines } \\
\text { Increased collagen production } \\
\text { Increased organoid stiffness }\end{array}$ & Ouchi et al. (2019) \\
\hline
\end{tabular}

PHHs, primary human hepatocytes; MPCC, micropatterned co-culture; hESCs, human embryonic stem cells; hiPSCs, human induced pluripotent stem cells; HLCs, hepatocyte-like cells.

increased expression of genes associated with insulin resistance includes phosphoenolpyruvate carboxykinase 1 (PCK1) mRNA, pyruvate dehydrogenase lipoamide kinase isozyme 4 (PDK4) mRNA, glucose-6-phosphatase mRNA, and fatty acid synthase mRNA, and decreased response of glycogen synthase kinase 3 (GSK3 3 ) to insulin all indicated insulin resistance (Kozyra et al., 2018). In a liver-on-a-chip model, the microfluidic dynamic system allows constant exposure to FFA. Therefore, it can imitate the chronic conditions of fat accumulation in line with clinical patients. Kostrzewski and colleagues established a $\mathrm{PHH}$ liver-on-a-chip model in which the PHHs were exposed to fat culture conditions $(600 \mu \mathrm{mol} / \mathrm{L}$ FFA under constant flow) for 14 days (Figures 2B,C), and then metabolic, transcriptome, and phenotypic changes were measured. Lipid accumulation and numerous transcriptional changes in genes associated with insulin resistance and lipid metabolism were noted from day 7, including increased CYP2E1, insulin-like growth factor (IGF $\beta 1$ ), PDK4, and CYP7A1 expressions. Meanwhile, the expression of inflammatory and fibrotic markers was noted, including interleukin-8 (IL-8), migration inhibitory factors, fibrinogen, and tissue inhibitor of metalloproteinase-1 (TIMP1) (Kostrzewski et al., 2017).

In contrast, $3 \mathrm{D}$ co-culture models can be used to imitate a more complex phenotype of NASH, such as liver fibrosis, gut-liver interaction, and chronic hyperglycemia exposure. For that, PHHs can be co-cultured with human KCs, HSCs, 3T3-J2 murine embryonic fibroblasts, or gastrointestinal cells together, as HSCs are the main collagen-producing cells during hepatic parenchymal injury, KCs play an essential role in inflammation, and 3T3-J2 murine embryonic fibroblasts help maintain $\mathrm{PHH}$ function in MPCC models. Davidson and colleagues developed a PHH MPCC model to mimic hyperglycemia-induced lipid accumulation. After 18 days of chronic exposure to hyperglycemia $(25 \mathrm{mM})$, MPCC showed more insulinaccumulated vesicles $(\sim 2.1$ fold $)$ than MPCC exposed to normoglycemic media $(5 \mathrm{mM})$. Impaired inhibitory effect of insulin (10 and $100 \mathrm{nM}$ ) on glucose output was observed in hyperglycemic MPCCs (detected glucose output reduced 70\%) when compared with normoglycemic MPCCs (completely undetectable). The altered nuclear-to-cytoplasmic ratio $(\mathrm{N}: \mathrm{C})$ of forkhead box O1 (FOXO1) in hyperglycemic MPCCs relative to normoglycemic MPCCs also implied abnormal influence of insulin on translocation of FOXO1 as seen in insulin-resistance patients (Davidson et al., 2016). The liveron-a-chip co-culture model represents similar disease progression to the MPCC model as well. Feaver et al. established liver-on-a-chip co-culture models that incorporated sinusoidal flow with PHHs, HSCs, and human macrophages. Upon 10 days of exposure to a lipotoxic environment consisting of elevated glucose $(25 \mathrm{mM})$, FFA $(110 \mu \mathrm{M})$, and insulin $(6,900$ pM) levels, the NASH phenotype was observed to be consistent with clinical NASH biopsies, manifesting as activated HSCs, insulin resistance (decreased sensitivity to insulin-mediated inhibition of glucose output and upregulated PCK1), mitochondrial dysfunction, increased oxidative stress (1.4-fold increased release of ALT and 2.6-fold increased CK-18), elevated inflammatory signaling (IL-8, IL-6, CXCL10, YKL40, upregulated toll-like receptors, and STATs), and increased fibrotic markers (TGF- $\beta$ and osteopontin) as well as lipid accumulation (Feaver et al., 2016). Moreover, co-culturing enterocytes and hepatic cell types together has the potential to recapitulate the whole process from absorption to metabolism of digestive lipids in NAFLD patients, while conventional models only focused on hepatic response to excessive FFA. Lee and Sung developed the first 
A

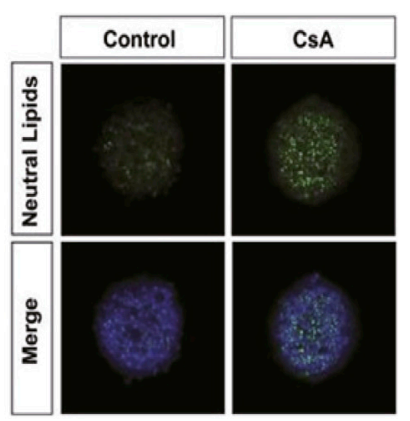

B

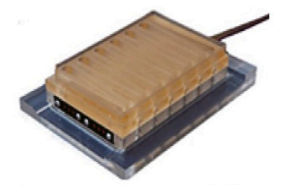

C

3D microtissue composed of cryopreserved human hepatocytes

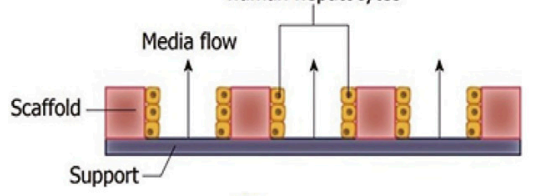

Lean
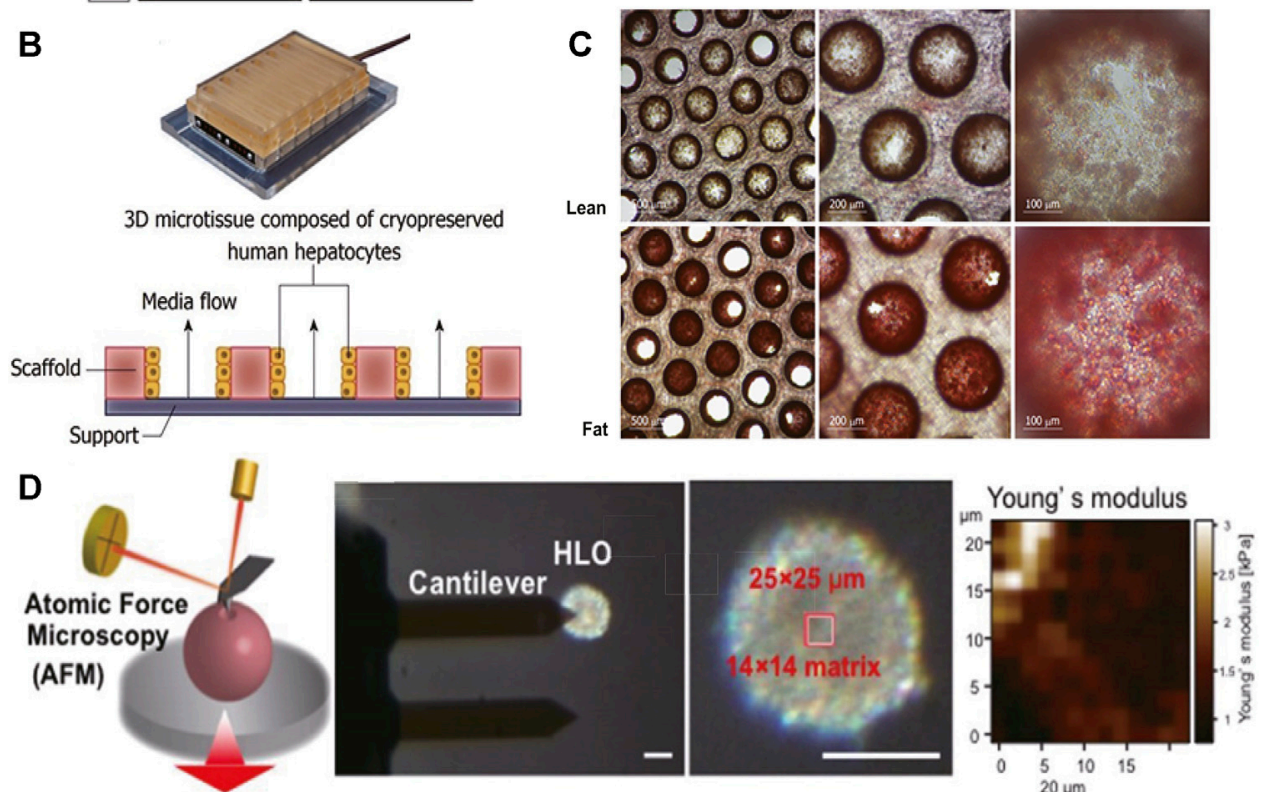

HLO stiffness quantification

FIGURE 2 | 3D cell culture paradigms support disease modeling of NAFLD. (A) Representative pictures of lipid accumulated in PHH spheroids upon exposure to cyclosporine A (30 $\mu \mathrm{M})$ for $48 \mathrm{~h}$; scale bars, $100 \mu \mathrm{m}$. (B) Illustration of the PHH liver-on-a-chip model. (C) Intracellular fat accumulation in the liver-on-a-chip model under fat condition (Lower) was noted after Oil Red O staining. (D) Schematic demonstration of stiffness measurement by AFM. The top region of each single organoid ( $14 \times 14$ matrix in a $25 \times 25 \mu \mathrm{m}$ square) was scanned with an AFM cantilever. Scale bar, $100 \mu \mathrm{m}$. Young's modulus on each scanned spot is shown in the heatmap. (A) Modified with permission from Bell et al. (2016). (B,C) Modified with permission from Kostrzewski et al. (2017). (D) Modified with permission from Ouchi et al. (2019).

gut-liver-on-a-chip model, in which Caco-2 enterocytes and HepG2 cells were incorporated in one chip. Upon treating the Caco-2 enterocytes with FFA for $24 \mathrm{~h}$, lipid accumulation in HepG2 cells was observed. The role of the pro-inflammatory cytokine TNF- $\alpha$ in the gut absorption permeability of lipids was further demonstrated in this model, indicating its application in addressing the multi-tissue etiology of NAFLD and exploring novel drug targets outside the liver (Lee and Sung, 2018).

Organoids derived from hiPSC/hESC-HLCs co-cultured with HSC- and KC-like cells were applied in this field as well. Ouchi and colleagues reported the simultaneous differentiation of hiPSCs/hESCs into tri-lineage liver organoids containing HLCs and HSC- and KC-like cells. Upon 5 days of persistent exposure to FFA (oleic acid), hiPSC/hESC-HLCs accumulated intracellular lipids; enlarged, HSC-like cells upregulated collagen production (increased vimentin, $\alpha$-smooth muscle actin, P3NP); and KC-like cells released pro-inflammatory cytokines (TNF- $\alpha$, IL-6, and IL8 ), recapitulating three key processes in NASH. Interestingly, organoid stiffness was measured by atomic force microscopy, and its increase likely reflected the severity of fibrosis (Figure 2D). Though the inter-batch variation in these organoids was reported in this experiment (Ouchi et al., 2019), it was proposed that stem cell-derived HLCs from patients would allow their specific NAFLD mechanisms to be assessed and benefit personalized medicine. For instance, patients with gene polymorphisms in patatin-like phospholipase-3 (PNPLA3) tend to suffer from highgrade NAFLD (Romeo et al., 2008), and stem cell-derived HLCs will allow the role of mutated gene in NAFLD to be studied. Meanwhile, advanced gene editing technology has the potential in not only revising diseased hiPSC-HLC organoids but also generating diseased hiPSC-HLC organoids with specific gene modulation as well (Alves-Bezerra et al., 2019; Cai et al., 2016). By contrast, these techniques might not be performed with patients' PHHs, which do not have sufficient long-term stability under in vitro culture conditions for gene editing and organoid generation. 

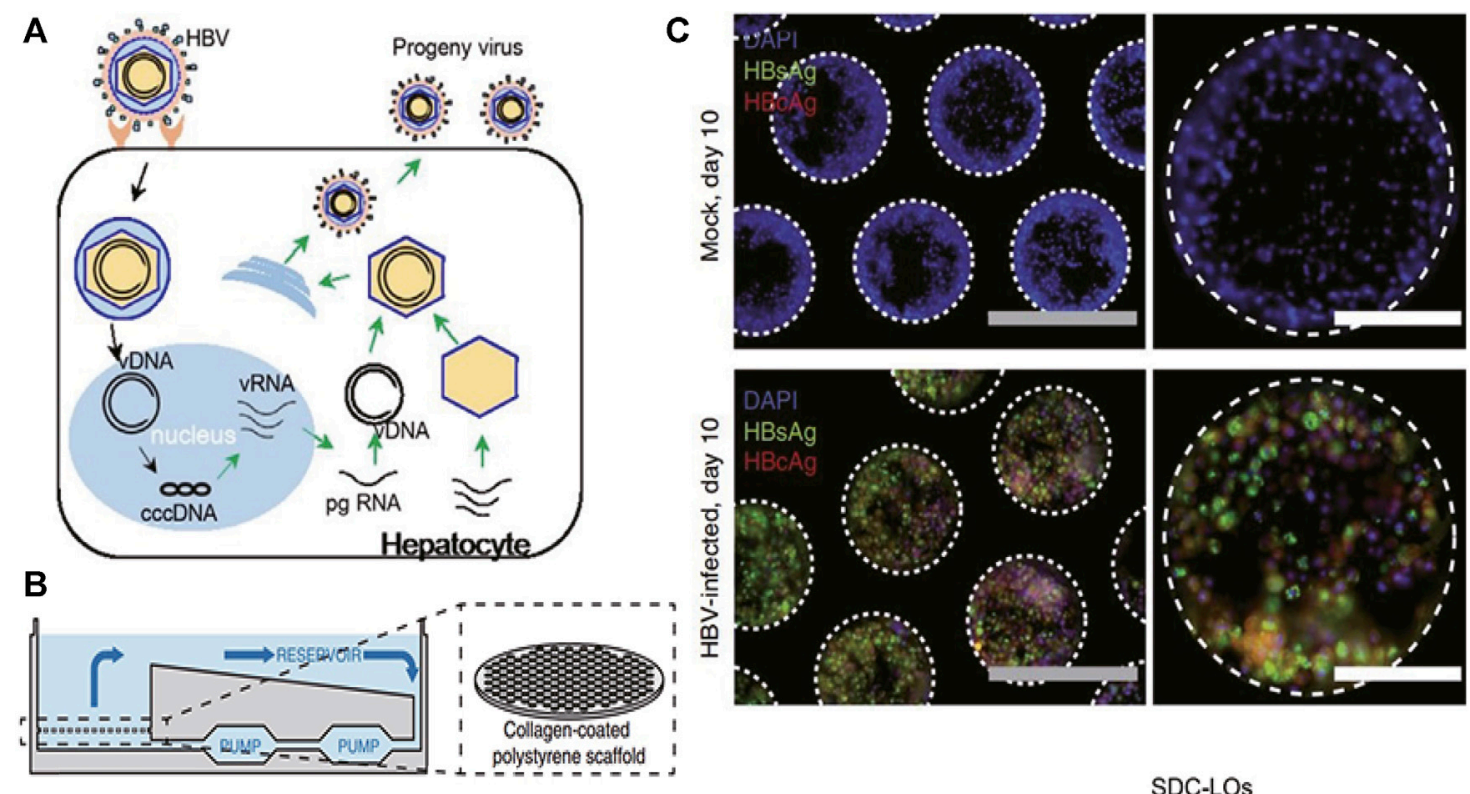

D
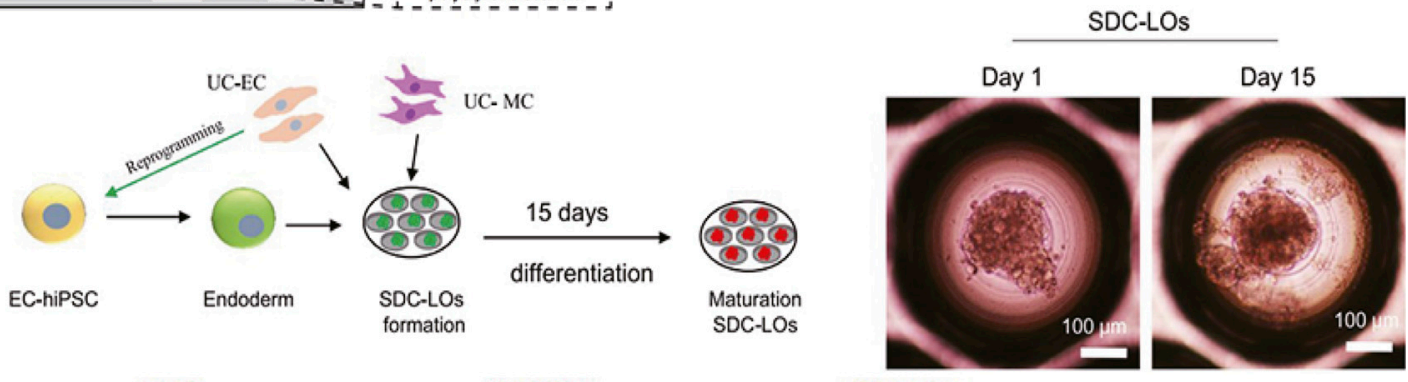

E
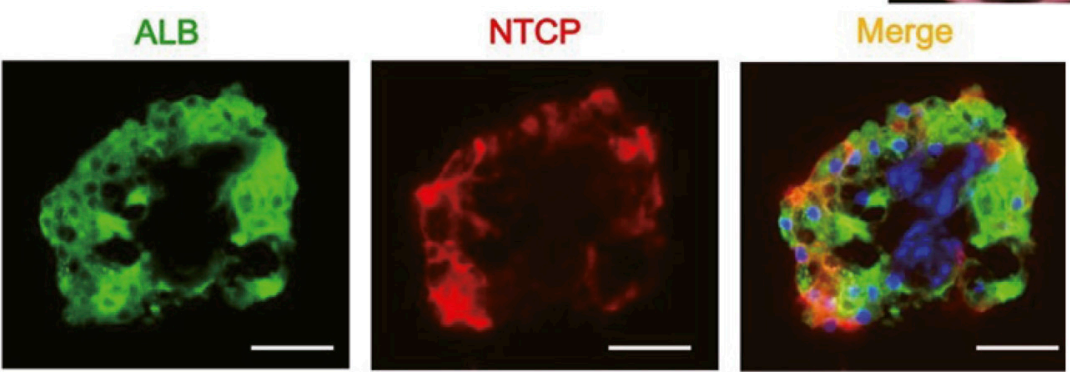

FIGURE 3| Selected representative 3D models of viral hepatitis B. (A) Schematic representation of the HBV life cycle in infected hepatocytes. (B) Illustration of the $\mathrm{PHH}$ liver-on-a-chip model. Microfluidic recirculation was driven by a micro-pump and went through collagen-coated polystyrene scaffolds seeded with PHHs. (C) Immunofluorescence of HBV viral antigens (HBsAg and HBcAg) 10 days following infection of the PHH liver-on-a-chip model with patient-derived HBV (100 GE/cell). (D) (Left) Schematic representation of the protocol for liver organoid generation and differentiation from single donor umbilical cord (UC)-derived hiPSCs, HUVECs, and mesenchymal cells (MCs). (Right) Morphology of single donor cell-derived liver organoids (SDC-LOs) on days 1 and 15. Scale bars, 100 um. (E) Immunofluorescence staining of ALB and NTCP in differentiated SDC-LOs. Green, ALB; red, NTCP. Scale bars, 50 m. (A) Modified with permission from Yan et al. (2012). (B,C) Modified with permission from Ortega-Prieto et al. (2018). (D,E) Modified with permission from Nie et al. (2018).

Collectively, human 3D hepatic in vitro NAFLD models were mainly derived from $\mathrm{PHH}$ cell type as it possesses in vivo-like metabolism of lipid and glucose and inducible insulin-resistance response. Importantly, they can be established by either monoculture or co-culture, depending on the phenotypes to be imitated. Compared with the mono-culture model, the coculture model is suitable for imitating more complex disease phenotypes. By incorporating 3T3-J2 murine embryonic fibroblasts, HSCs, KCs, or gastrointestinal cells with $\mathrm{PHHs}$ together, MPCC, organ-chip, and organoid co-culture models have been established, which successfully imitated liver fibrosis, gut-liver interaction, and chronic hyperglycemia exposure. In addition to pathogenesis modeling, several anti-NAFLD drug compounds have been tested based on PHH models (Bell et al., 2016; Feaver et al., 2016; Kostrzewski et al., 2017; Kozyra et al., 2018; Lee and Sung, 2018), indicating the PHH model can be a solution to accumulate sufficient preclinical evidence for clinical drug development. Furthermore, though current inter-batch variation in hiPSC-HLC-derived organoids was non-negligible, stem cell-derived HLCs would benefit personalized in vitro 
NAFLD modeling, which could be the significant advancement in the future modeling paradigm (Romeo et al., 2008; Alves-Bezerra et al., 2019; Ouchi et al., 2019).

\section{Viral Hepatitis}

Viral hepatitis mostly results from hepatotropic virus A, B, C, D, and $\mathrm{E}$ infections through the fecal-oral, parenteral, perinatal, or sexual route. Among them, chronic HBV and HCV infections particularly lead to hepatic parenchymal damage including liver cirrhosis and HCC, and they are responsible for about $90 \%$ of viral hepatitis-leading annual deaths (Wiktor and Hutin, 2016). Current viral hepatitis modeling mainly focuses on HBV infection. HBV genome is a small $(3.2 \mathrm{~kb})$ and partially double-strand DNA, which persists as a covalently closed, circular (ccc) DNA episome (Figure 3A). This cccDNA is the transcriptional template for pregenomic (pg) RNA and subgenomic (sg) RNA species. Sodium-taurocholate cotransporting polypeptide (NTCP) was identified as one of the HBV entry receptors (Yan et al., 2012).

The goal in imitating HBV infection is to establish in vitro models that support productive infection and mimic virus-host interaction accurately, which will benefit the drug development targeting-specific viral life cycle and host responsiveness. PHH 2D mono-culture was thought to lose its permissiveness to HBV infection due to down-regulation of NTCP expression after isolation and subsequent culture (Yan et al., 2012). Therefore, Shlomai and colleagues co-cultured $\mathrm{PHHs}$ and stromal fibroblasts (3T3-J2 murine embryonic fibroblasts) in the MPCC model to mimic HBV infection. After exposure to HBV infectious serum at multiplicity of infection (MOI) of 300 HBV GE/cell, this MPCC model stably expressed NTCP receptors over 14 days and supported productive HBV infection over 21 days, reflected by robust viral gene expression including HBV surface antigen (HBsAg) secretion, $\mathrm{HBV}$ transcript mRNA production, $\mathrm{HBV}$ core antigen ( $\mathrm{HBcAg}$ ) expression, and the presence of high viral cccDNA copies. Innate immune response was observed as upregulated antiviral interferon-stimulated genes (ISGs) including interferon (IFN)- $\alpha$ and IFN- $\beta$, which were mainly induced after 7 days of infection (Shlomai et al., 2014).

Ortega-Prieto et al. mono-cultured PHHs in the liver-on-achip model (Figure 3B) to build a more natural host cell environment resembling liver sinusoids. $\mathrm{HBcAg}$, $\mathrm{HBsAg}$ (Figure 3C), cccDNA, and HBV replication intermediates (sgRNA, pgRNA) were noted as well when treated with 100 GE/cell patient-derived HBV. Furthermore, both IFN- $\alpha$ and IFN$\beta$ were suppressed to $10 \%$ of the levels observed in mock-infected cultures, suggesting an active role of HBV in suppressing innate immune activation. Similar to the findings in the sera of HBVinfected patients, significantly elevated protein levels of IL-8, macrophage-inflammatory protein (MIP)-3a, SerpinE1, and monocyte chemotactic protein-1 (MCP-1) were observed in HBV-infected liver-on-a-chip models. Furthermore, to identify the role of non-parenchymal cells in HBV infection, OrtegaPrieto et al. co-cultured PHHs and KCs together in the above model. Surprisingly, except for the elevated level of C-reaction protein (CRP), virological characteristics of $\mathrm{HBV}$ infection including secreted levels of $\mathrm{HBsAg}$, hepatitis $\mathrm{B}$ e antigen (HBeAg), pgRNA, and sgRNA were identical in mono-culture and co-culture, and $\mathrm{KC}$-specific cytokines IL- 6 and TNF- $\alpha$ were not secreted as well, indicating that $\mathrm{HBV}$ evaded the immunosurveillance function of liver-resident macrophages (Ortega-Prieto et al., 2018).

As illustrated in Figure 3D, Nie and colleagues co-cultured hiPSC-derived endoderm cells, human bone marrow mesenchymal cells, and human umbilical vein endothelial cells (HUVECs) together to establish a liver organoid that exhibited stronger hepatic functions and more susceptibility to HBV infection than hiPSC-HLC mono-culture organoids. Significantly increased expression levels of the NTCP (Figure 3E), viral pgRNA, cccDNA, and supernatant viral DNA were observed in organoids from the sixth day postinfection and can be maintained to at least 20 days postinfection. Meanwhile, infectious progeny viruses could still be produced from infected organoids at 20 days post-infection, suggesting this model could serve as a long-term in vitro infection model. Furthermore, the expression of HBcAg and known infection-promoting factors including glypican 5 (GPC5), peroxisome proliferator-activated receptor alpha (PPARA), and CCAAT/enhancer-binding protein alpha (CEBPA) was detected. Viral dose-dependent hepatic dysfunction with down-regulation of hepatic gene expression, induced release of early acute liver failure markers, and altered hepatic ultrastructure were noted, indicating this organoid could be a robust infection model representing viral host response (Nie et al., 2018).

As concluded in Table 4, PHHs and hiPSC-HLCs were proved to be suitable for modeling HBV infection as they recapitulate viral replicating cycles and viral-host interaction. Though the HepG2 cell line was susceptible to HBV infection as well (Sells et al., 1987; Gripon et al., 2002; Lucifora et al., 2010), concerning the virus-host interaction, it is not a suitable cell system since no ISG induction was observed after viral exposure, which was probably caused by defective HBV sensors or key transducers in this sensing pathway (Shlomai et al., 2014). Moreover, divergence in host response was observed in PHHs from different donors, implying the HLC cell model derived from hiPSCs or hASCs may benefit personalized treatment. Regarding the culture paradigm, in previous $2 \mathrm{D}$ models, PHHs and hiPSC-HLCs both supported HBV and HCV infections, which cannot sustain in the long term due to rapid loss of hepatic function (Roelandt et al., 2012; Schwartz et al., 2012; Shlomai et al., 2014). MPCC, liver-on-a-chip, and organoid models are more susceptible to HBV infection than the spheroid model since the central cells of spheroids are hard to get access to virus, and the infection was proved to be more effective if performed upon seeding rather than when cells had aggregated into spheroids (Bell et al., 2016). Besides, MPCC, liver-on-a-chip, and organoid models all support antiviral drug testing, such as HBV entry inhibitors, anti-HBV nucleoside, HBV reverse transcriptase inhibitors, and IFNa, validating these models as preclinical platforms for evaluating the novel treatment strategy (Shlomai et al., 2014; Nie et al., 2018; Ortega-Prieto et al., 2018). 
TABLE 4 | Selected 3D viral hepatitis models established from different cell types.

\begin{tabular}{|c|c|c|c|c|c|}
\hline Cell type & Culture paradigm & $\begin{array}{l}\text { Culture } \\
\text { period }\end{array}$ & Endpoints & Application & References \\
\hline $\mathrm{PHHs}$ & MPCC co-culture & 21 days & $\begin{array}{l}\text { Expression of NTCP receptors } \\
\text { Expression of HBsAg and } \mathrm{HBcAg} \\
\text { Expression of HBV DNA and replication intermediates } \\
\text { Induced ISG gene expression }\end{array}$ & $\begin{array}{l}\text { Disease modeling: HBV } \\
\text { infection }\end{array}$ & Shlomai et al. (2014) \\
\hline $\mathrm{PHHs}$ & $\begin{array}{l}\text { Liver-on-a-chip mono- } \\
\text { culture }\end{array}$ & 22 days & $\begin{array}{l}\text { Expression of HBsAg and HBcAg } \\
\text { Expression of HBV DNA and replication intermediates } \\
\text { Suppressed baseline innate immune activation } \\
\text { Similar chemokine and cytokine responses as seen in } \\
\text { HBV-infected patients }\end{array}$ & $\begin{array}{l}\text { Disease modeling: HBV } \\
\text { infection }\end{array}$ & $\begin{array}{l}\text { Ortega-Prieto et al. } \\
\text { (2018) }\end{array}$ \\
\hline $\begin{array}{l}\text { hiPSC- } \\
\text { HLCs }\end{array}$ & Organoid co-culture & 42 days & $\begin{array}{l}\text { Expression of NTCP receptors } \\
\text { Expression of HBV DNA and replication intermediates } \\
\text { Expression of HBcAg and known infection-promoting } \\
\text { factors } \\
\text { Viral dose-dependent hepatic dysfunction }\end{array}$ & $\begin{array}{l}\text { Disease modeling: HBV } \\
\text { infection }\end{array}$ & Nie et al. (2018) \\
\hline
\end{tabular}

PHHs, primary human hepatocytes; hiPSCs, human induced pluripotent stem cells; HLCs, hepatocyte-like cells; NTCP, sodium-taurocholate co-transporting polypeptide; ISG, interferonstimulated gene; MPCC, micropatterned co-culture; HBCAg, HBV core antigen.

\section{Monogenetic Liver Disease}

Resulting from mutation in one single gene, monogenic liver diseases include a group of hepatic functional disorders and can be divided into two types: one is manifesting as predominant hepatic parenchymal damage and the other is liver-based genetic disorders with an architecturally near-normal liver. This review focuses on the former since disease manifestations of this type are more likely to be fully recapitulated in hepatic models. The representative diseases are A1AT deficiency, Wilson's disease, and Wolman's disease. With mutation in the SERPINA1 gene, A1AT deficiency results in decreased normal A1AT which protects the hepatic and pulmonary parenchyma from proteolytic damage of neutrophil elastase, predisposing to chronic hepatic and obstructive pulmonary diseases. The accumulation of misfolded A1AT in the endoplasmic reticulum (ER) of hepatocytes also triggers ER stress and apoptosis (Greene et al., 2016). With mutation in the ATP7B gene, Wilson's disease results in inadequate functional coppertransporting ATPase 2, which transports copper out of the liver and prevents intracellular copper accumulation. Copper overload causes hepatocyte death and uncontrolled release of copper in the circulation (Ala et al., 2007). With mutation in the lysosomal acid lipase (LAL) gene, Wolman's disease results in accumulation of lipids due to lack of the LAL enzyme and abnormal enzymatic breakdown of triglycerides, accompanied by hepatomegaly and lethal steatohepatitis (Pericleous et al., 2017). Though originated in different genetic backgrounds, underlying mechanisms of all these disorders involve continuous inflammation, parenchymal necrosis, abnormal hepatocyte regeneration, and ultimately the development of hepatic failure.

For Wolman's disease, Ouchi and colleagues derived organoids from the patient's hiPSC-HLCs. Upon exposure to oleic acid, prominent lipid accumulation in Wolman's disease organoids compared with normal hiPSC-derived organoids was noted (Figure 4A), and it was rescued after exposure to recombinant LAL protein. 11.22-fold fibrotic marker P3NP (2.8-fold in normal hiPSC-derived organoids) and significantly increased stiffness further suggest Wolman's disease organoids exhibit more aggressive fibrosis phenotypes (Figure 4B) as seen in clinical patients (Ouchi et al., 2019).

Huch and colleagues developed the A1AT deficiency organoid model via using hASCs (EpCAM+) obtained from patient biopsies with homozygous $(Z Z)$ A1AT mutants. After 22 days of expansion and differentiation, around $67 \%$ reduced A1AT secretion in the culture supernatant accompanied by reduced elastase inhibition and sign of increased ER stress (increased phosphorylation of eIF2a) was noted, indicating successful imitation of hallmarks of A1AT deficiency in vitro (Figure 4D). Meanwhile, similar to those found in the original patient biopsies, aggregated A1AT proteins were observed after 11 days of differentiation under immunohistochemistry staining (Figures 4E-H) (Huch et al., 2015). Furthermore, to study the genotype-specific feature in A1AT deficiency, Gomez-Mariano and colleagues took 35 days to establish organoids from liver biopsies of patients with the homozygous $(Z Z)$ variant, the heterozygous $(M Z)$ variant, and normal $(M M)$ genotypes of A1AT. In contrast to $M M$ phenotypes, a lower transcription level of the SERPINA1 gene was found in $Z Z$ organoids. Upon immunohistostaining and quantification of cells positive for the A1AT polymer, $5 \%, 10 \%$ of cells in $M Z, Z Z$ organoids exhibited polymer accumulation, respectively (Figure 4C). Meanwhile, western blot revealed that the monomeric A1AT protein was detected in the extracellular medium and cell extracts of $M M$, $M Z$, but not $Z Z$ organoids, while the largest amount of insoluble A1AT was present in $Z Z$ compared to $M Z$ or $M M$ organoids. The above findings reflecting genotype-specific features were also observed in patients (Gomez-Mariano et al., 2020). Since there is no consensus guideline for these monogenic diseases and the current ameliorative strategies are expensive, these organoid models were further exploited to investigate the therapeutic potential of drug compounds to reverse the phenotype of lipid accumulation and stiffness (Ouchi et al., 2019), or induce 

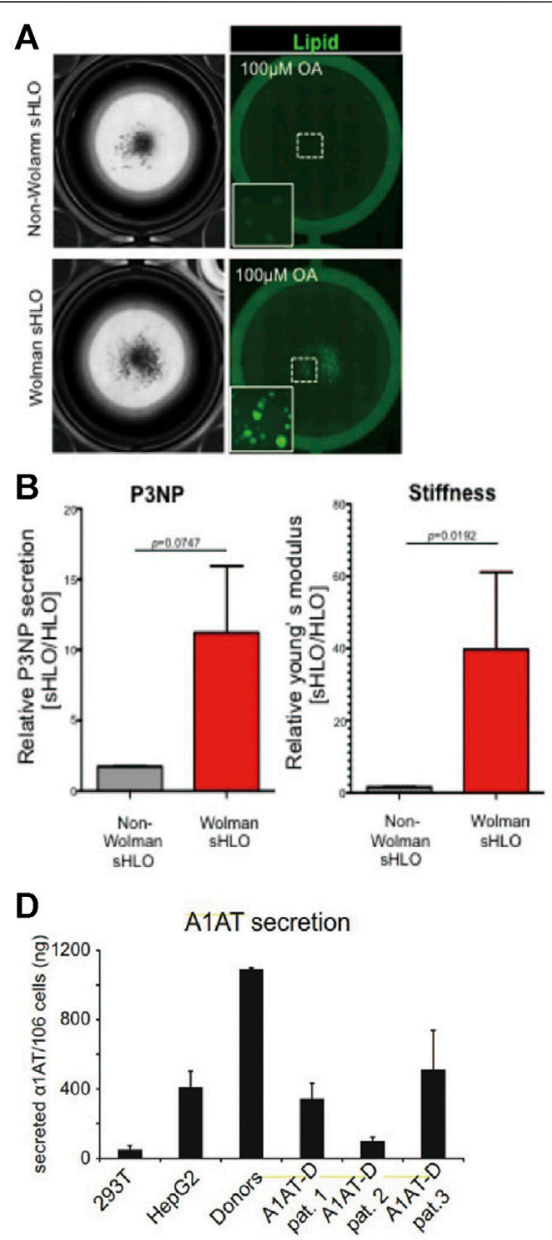

C
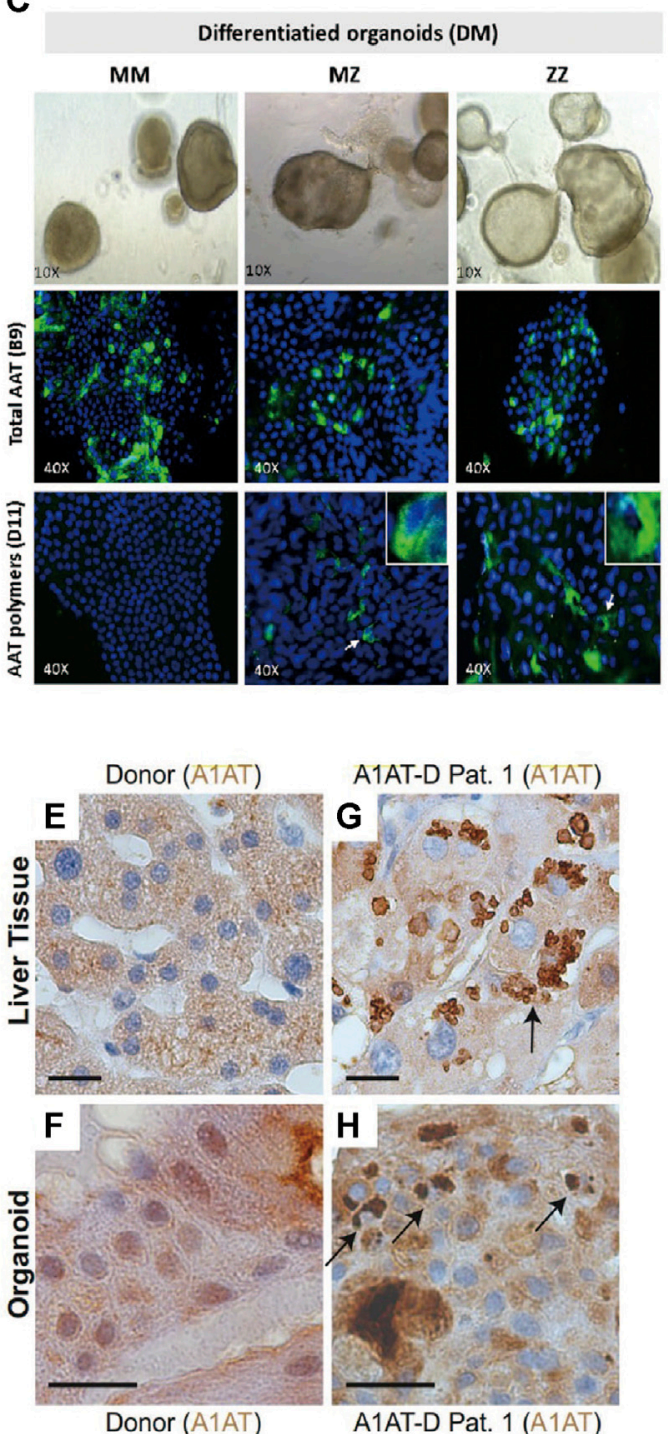

FIGURE 4 | Selected representative 3D models of monogenic diseases. (A) Representative bright-field and lipid-fluorescent images of organoids from Wolman disease patients and non-Wolman donors after oleic acid treatment. (B) (Left) Comparison of the P3NP secretion level of non-Wolman and Wolman human liver organoids (HLOs). (Right) Comparison of Young's modulus of non-Wolman and Wolman organoids, $n=7$. (C) Differentiated liver organoids from MM, MZ, and ZZ patients. Specific detection of total AAT protein with anti-AAT-B9 and AAT polymers with anti-AAT-D11 is shown in green fluorescence. (D) ELISA measurement of A1AT secretion in supernatants from healthy donor and patient organoids after 11 days of differentiation. (E-H) Immunohistochemistry for A1AT on liver tissue (E,G) and liver-derived organoids from a healthy donor (F) and a representative A1AT deficiency patient (H). Black arrows indicate A1AT proteins aggregated in patient-derived liver tissue (G) and organoids (H). Scale bars, $20 \mathrm{~mm}$. All results are represented as mean \pm SEM. Figure modified with permission from Ouchi et al. (2019), Gomez-Mariano et al. (2020), and Huch et al. (2015).

increased expression of full length or short transcripts of A1AT (Gomez-Mariano et al., 2020).

In summary, current $3 \mathrm{D}$ cell models of monogenic diseases are mainly developed via using the patient-derived cell sample, including hASCs isolated from liver biopsy and hiPSCs (Table 5). These studies are proof-of-principle that liver organoids recapitulated key features of the disease in vitro. Development of the model derived from the patient's materials is valuable since the mutation of alleles in one single gene is diverse. Together with environmental and epigenetic factors, they all may lead to different clinical presentation of diseases, while cell samples from patients fill this research gap and recapitulate the genetic background of individuals. Combined with gene editing, specific genetic therapy can be designed to benefit personalized treatment based on these patient-derived organoid models.

\section{Hepatocyte Transplantation}

Liver transplantation is the accepted treatment for patients with end-stage liver failure, while shortage of liver donors and lifelong need for immunosuppression are critical challenges for accepting 
TABLE 5 | Selected 3D monogenic liver disease models established from different cell types.

\begin{tabular}{|c|c|c|c|c|c|}
\hline Cell type & Culture paradigm & $\begin{array}{l}\text { Culture } \\
\text { period }\end{array}$ & Endpoints & Application & References \\
\hline $\begin{array}{l}\text { Patient's hASC- } \\
\text { HLCS }\end{array}$ & $\begin{array}{l}\text { Organoid mono- } \\
\text { lineage }\end{array}$ & 22 days & $\begin{array}{l}\text { Decreased A1AT secretion } \\
\text { Polymerized A1AT intracellular } \\
\text { aggregation } \\
\text { Reduced ability to block elastase activity } \\
\text { Increased ER stress }\end{array}$ & $\begin{array}{l}\text { Disease modeling: A1AT } \\
\text { deficiency }\end{array}$ & Huch et al. (2015) \\
\hline $\begin{array}{l}\text { Patient's hASC- } \\
\text { HLCs }\end{array}$ & $\begin{array}{l}\text { Organoid mono- } \\
\text { lineage }\end{array}$ & 35 days & $\begin{array}{l}\text { Decreased SERPINA1 transcriptional } \\
\text { expression } \\
\text { Decreased normal A1AT secretion } \\
\text { Polymerized A1AT intracellular } \\
\text { aggregation }\end{array}$ & $\begin{array}{l}\text { Disease modeling: A1AT } \\
\text { deficiency }\end{array}$ & $\begin{array}{l}\text { Gomez-Mariano et al. } \\
\text { (2020) }\end{array}$ \\
\hline $\begin{array}{l}\text { Patient's hiPSC- } \\
\text { HLCS }\end{array}$ & $\begin{array}{l}\text { Organoid mono- } \\
\text { lineage }\end{array}$ & 25 days & $\begin{array}{l}\text { Hepatic lipid accumulation } \\
\text { Increased fibrotic marker } \\
\text { Increased stiffness }\end{array}$ & $\begin{array}{l}\text { Disease modeling: Wolman's } \\
\text { disease }\end{array}$ & Ouchi et al. (2019) \\
\hline
\end{tabular}

hASCs, human adult stem cells; HLCs, hepatocyte-like cells; hiPSCs, human induced pluripotent stem cells; A1AT, alpha-1 antitrypsin.

allogenic liver transplantation. Meanwhile, hepatocyte transplantation as an alternative to liver transplantation is also impeded by shortage and the expanding challenge of $\mathrm{PHHs}$ (Iansante et al., 2018). Under these circumstances, generating in vivo liver tissue like a $3 \mathrm{D}$ hepatic model in vitro with pluripotent stem cell-derived HLCs becomes an important issue, which enables homologous hepatocyte transplantation with the potential of limiting immune rejection. For transplantation, maturity and complete function of established liver tissue are significant. Current studies co-cultured hiPSCs with various types of supporting non-parenchymal cells to attain a higher differentiation yield and to improve HLC functions both in vitro and in vivo. Organoid models established from pluripotent stem cell-derived HLCs or using 3D bioprinting technology are promising to provide possible solutions (Takebe et al., 2013; Hu et al., 2018; Pettinato et al., 2019; Yang et al., 2021). The idea of applying hiPSC/liver progenitor-HLC organoids in regenerative medicine is based on the natural regeneration of the liver. Liver progenitor cell-driven regeneration was reported upon liver injury. During this process, preexisting hepatocytes or biliary epithelial cells dedifferentiated into liver progenitor cells, followed by proliferation and differentiation of progenitor cells into hepatocytes to rapidly restore tissue mass (Yanger et al., 2014; So et al., 2020).

Takebe and colleagues co-cultured hiPSC-hepatic endodermal cells with human mesenchymal stem cells (MSCs) and HUVECs to generate an organoid that developed into hepatic tissue in vivo upon transplantation into NOD/SCID mice. The three cell lineages spontaneously formed a vascular-like endothelial network and organized into $3 \mathrm{D}$ organoid tissue in vitro, resembling the in vivo liver bud through immunohistochemistry staining and gene expression analysis. The vasculature in organoids successfully connected to the host vessels within $48 \mathrm{~h}$, stimulating its maturation into adult liver-like tissue in vivo. Liver-specific function including albumin secretion and human-specific ketoprofen and debrisoquine metabolism were reported in mice after transplantation. Moreover, mesenteric transplantation of the liver bud rescued drug- induced acute liver failure in the TK/NOD mouse model, suggesting the use of hiPSC-HLC organoids as a novel source for liver transplantation (Takebe et al., 2013). Yang et al. constructed the liver organoid derived from HepaRG and bioink following specific $3 \mathrm{D}$ bioprinting procedures and proved its liver functions in vitro and in vivo. In this study, the HepaRG cell line was selected for its dual potential to differentiate into functional hepatocytes and cholangiocytes. Hepatic functions including albumin secretion, drug metabolism, and glycogen storage were detected after 7 days of differentiation of HepaRG in vitro. Upon transplanted into the $\mathrm{Fah}^{-/-} \mathrm{Rag}^{-/-}$mouse model of liver injury, 3DP-HOs displayed functional vasculature, increased synthesis of liver-specific proteins including human albumin, A1AT, and factors VII and IX, and exhibited human-specific debrisoquine metabolism. Significantly, transplantation of 3DP-HOs prolonged the cumulative survival of mice from 32 to 56 days and decreased the weight loss, indicating that $3 \mathrm{D}$ bioprinting could be used to generate human liver tissues as the alternative transplantation donors. Interestingly, the authors conducted a pilot study investigating different cell types in 3D bioprinting and indicated that the survival rate of $\mathrm{PHH}$ after printing was too low (less than 10\%), and the in vitro liver functions of HepG2 cell lines were also not satisfactory. Among all tested cell types, the HepaRG cell line is the most appropriate alternative to PHHs because it possesses differentiation capability and comparable hepatic metabolic properties (Yang et al., 2021).

\section{CONCLUSION}

Rapidly emerging in vitro human hepatic 3D models maintaining hepatic phenotypes and functions increase the predictability of DILI, allow for faithful metabolite profiling and disease imitating, and benefit exploration of idiosyncratic drug effects as well. PHHs, HepaRG, HepG2, hiPSC/hESC-HLCs, and hASC-HLCs were mostly involved in the above applications. Indicated by recent studies, different hepatic cell types possess unique genetic and protein expression profiles and show specific advantages in 
divergent research fields. Compared to HepaRG, HepG2, and all stem cell-HLCs, PHH cell type in the spheroid or MPCC model shows superior sensitivity, specificity, and convenience in drug hepatotoxicity screening. PHH MPCC models, supported by mouse embryonic 3T3 fibroblasts, show extended cell viability typically up to 6 weeks with sustained hepatic functions. Therefore, the PHH MPCC model particularly benefits metabolite profiling for drugs with low clearance. For idiosyncratic drug effect study, both $\mathrm{PHH}$ and hiPSC/hASCHLCs obtained from patients are recommended. In the field of disease modeling, co-culture models incorporating HSCs, KCs, or gastrointestinal cells with $\mathrm{PHH}$ or hiPSC/hASC-HLCs together were suitable for imitating more complex disease phenotypes and show faithful disease-modulated immune response. Liver-on-achip, liver-gut-on-a-chip, and organoid models resemble human physiological structure and provide a more faithful in vivo-like environment. Current 3D models of monogenic diseases are organoid models derived from the patient-derived cell sample, including hASCs isolated from liver biopsy and hiPSCs. Healthy organoids derived from human stem cells/liver progenitor cells or

\section{REFERENCES}

Ala, A., Walker, A. P., Ashkan, K., Dooley, J. S., and Schilsky, M. L. (2007). Wilson's Disease. Lancet 369 (9559), 397-408. doi:10.1016/s0140-6736(07)60196-2

Allegrucci, C., and Young, L. E. (2007). Differences between Human Embryonic Stem Cell Lines. Hum. Reprod. Update 13 (2), 103-120. doi:10.1093/humupd/dml041

Alves-Bezerra, M., Furey, N., Johnson, C. G., and Bissig, K.-D. (2019). Using CRISPR/Cas9 to Model Human Liver Disease. JHEP Rep. 1 (5), 392-402. doi:10.1016/j.jhepr.2019.09.002

Andersson, T. B., Kanebratt, K. P., and Kenna, J. G. (2012). The HepaRG Cell Line: a Uniquein Vitrotool for Understanding Drug Metabolism and Toxicology in Human. Expert Opin. Drug Metab. Toxicol. 8 (7), 909-920. doi:10.1517/ 17425255.2012.685159

Ang, L. T., Tan, A. K. Y., Autio, M. I., Goh, S. H., Choo, S. H., Lee, K. L., et al. (2018). A Roadmap for Human Liver Differentiation from Pluripotent Stem Cells. Cel Rep. 22 (8), 2190-2205. doi:10.1016/j.celrep.2018.01.087

Aninat, C., Piton, A., Glaise, D., Le Charpentier, T., Langouët, S., Morel, F., et al. (2006). Expression of Cytochromes P450, Conjugating Enzymes and Nuclear Receptors in Human Hepatoma HepaRG Cells. Drug Metab. Dispos. 34 (1), 75-83. doi:10.1124/dmd.105.006759

Ardalani, H., Sengupta, S., Harms, V., Vickerman, V., Thomson, J. A., and Murphy, W. L. (2019). 3-D Culture and Endothelial Cells Improve Maturity of Human Pluripotent Stem Cell-Derived Hepatocytes. Acta Biomater. 95, 371-381. doi:10.1016/j.actbio.2019.07.047

Asrani, S. K., Devarbhavi, H., Eaton, J., and Kamath, P. S. (2019). Burden of Liver Diseases in the World. J. Hepatol. 70 (1), 151-171. doi:10.1016/ j.jhep.2018.09.014

Barros, S. A., and Martin, R. B. (2008). Predictive Toxicogenomics in Preclinical Discovery. Methods Mol. Biol. 460, 89-112. doi:10.1007/978-1-60327-048-9_5

Baxter, M., Withey, S., Harrison, S., Segeritz, C.-P., Zhang, F., Atkinson-Dell, R., et al. (2015). Phenotypic and Functional Analyses Show Stem Cell-Derived Hepatocyte-like Cells Better Mimic Fetal rather Than Adult Hepatocytes. J. Hepatol. 62 (3), 581-589. doi:10.1016/j.jhep.2014.10.016

Bell, C. C., Hendriks, D. F. G., Moro, S. M. L., Ellis, E., Walsh, J., Renblom, A., et al. (2016). Characterization of Primary Human Hepatocyte Spheroids as a Model System for Drug-Induced Liver Injury, Liver Function and Disease. Sci. Rep. 6, 25187. doi:10.1038/srep25187

Bell, C. C., Lauschke, V. M., Vorrink, S. U., Palmgren, H., Duffin, R., Andersson, T. B., et al. (2017). Transcriptional, Functional, and Mechanistic Comparisons of Stem Cell-Derived Hepatocytes, HepaRG Cells, and Three-Dimensional Human Hepatocyte Spheroids as Predictive In Vitro Systems for Drug- combined with 3D printing materials are promising for liver transplantation.

\section{AUTHOR CONTRIBUTIONS}

QX contributed all to this work.

\section{FUNDING}

This work was supported by the Hong Kong Baptist University Undergraduate Research Programme (RC/UGSRP-03).

\section{ACKNOWLEDGMENTS}

Thanks are due to the Hong Kong Baptist University Research Committee and School of Chinese Medicine, Hong Kong Baptist University.

Induced Liver Injury. Drug Metab. Dispos. 45 (4), 419-429. doi:10.1124/ dmd.116.074369

Bell, C. C., Dankers, A. C. A., Lauschke, V. M., Sison-Young, R., Jenkins, R., Rowe, C., et al. (2018). Comparison of Hepatic 2D Sandwich Cultures and 3D Spheroids for Long-Term Toxicity Applications: A Multicenter Study. Toxicol. Sci. 162 (2), 655-666. doi:10.1093/toxsci/kfx289

Berger, B., Donzelli, M., Maseneni, S., Boess, F., Roth, A., Krähenbühl, S., et al. (2016). Comparison of Liver Cell Models Using the Basel Phenotyping Cocktail. Front. Pharmacol. 7, 443. doi:10.3389/fphar.2016.00443

Boeckmans, J., Natale, A., Buyl, K., Rogiers, V., De Kock, J., Vanhaecke, T., et al. (2018). Human-based Systems: Mechanistic NASH Modelling Just Around the Corner? Pharmacol. Res. 134, 257-267. doi:10.1016/j.phrs.2018.06.029

Cai, J., Zhao, Y., Liu, Y., Ye, F., Song, Z., Qin, H., et al. (2007). Directed Differentiation of Human Embryonic Stem Cells into Functional Hepatic Cells. Hepatology 45 (5), 1229-1239. doi:10.1002/hep.21582

Cai, L., Fisher, A. L., Huang, H., and Xie, Z. (2016). CRISPR-mediated Genome Editing and Human Diseases. Genes Dis. 3 (4), 244-251. doi:10.1016/ j.gendis.2016.07.003

Calabrese, D., Roma, G., Bergling, S., Carbone, W., Mele, V., Nuciforo, S., et al. (2019). Liver Biopsy Derived Induced Pluripotent Stem Cells Provide Unlimited Supply for the Generation of Hepatocyte-like Cells. PLoS One 14 (8), e0221762. doi:10.1371/journal.pone.0221762

Carpentier, A., Tesfaye, A., Chu, V., Nimgaonkar, I., Zhang, F., Lee, S. B., et al. (2014). Engrafted Human Stem Cell-Derived Hepatocytes Establish an Infectious HCV Murine Model. J. Clin. Invest. 124 (11), 4953-4964. doi:10.1172/jci75456

Chalasani, N., and Björnsson, E. (2010). Risk Factors for Idiosyncratic DrugInduced Liver Injury. Gastroenterology 138 (7), 2246-2259. doi:10.1053/ j.gastro.2010.04.001

Cheung, C., and Gonzalez, F. J. (2008). Humanized Mouse Lines and Their Application for Prediction of Human Drug Metabolism and Toxicological Risk Assessment. J. Pharmacol. Exp. Ther. 327 (2), 288-299. doi:10.1124/ jpet.108.141242

Cox, C. R., Lynch, S., Goldring, C., and Sharma, P. (2020). Current Perspective: 3D Spheroid Models Utilizing Human-Based Cells for Investigating Metabolismdependent Drug-Induced Liver Injury. Front. Med. Technol. 2 (14). doi:10.3389/fmedt.2020.611913

Cui, X., Hartanto, Y., and Zhang, H. (2017). Advances in Multicellular Spheroids Formation. J. R. Soc. Interf. 14 (127), 20160877. doi:10.1098/rsif.2016.0877

Dao Thi, V. L., Wu, X., Belote, R. L., Andreo, U., Takacs, C. N., Fernandez, J. P., et al. (2020). Stem Cell-Derived Polarized Hepatocytes. Nat. Commun. 11 (1), 1677. doi:10.1038/s41467-020-15337-2 
Davidson, M. D., Ballinger, K. R., and Khetani, S. R. (2016). Long-term Exposure to Abnormal Glucose Levels Alters Drug Metabolism Pathways and Insulin Sensitivity in Primary Human Hepatocytes. Sci. Rep. 6, 28178. doi:10.1038/srep28178

Derakhshanfar, S., Mbeleck, R., Xu, K., Zhang, X., Zhong, W., and Xing, M. (2018). 3D Bioprinting for Biomedical Devices and Tissue Engineering: A Review of Recent Trends and Advances. Bioactive Mater. 3 (2), 144-156. doi:10.1016/ j.bioactmat.2017.11.008

Donato, M. T., and Tolosa, L. (2021). High-Content Screening for the Detection of Drug-Induced Oxidative Stress in Liver Cells. Antioxidants 10 (1), 106. doi:10.3390/antiox10010106

Dorrell, C., Tarlow, B., Wang, Y., Canaday, P. S., Haft, A., Schug, J., et al. (2014). The Organoid-Initiating Cells in Mouse Pancreas and Liver Are Phenotypically and Functionally Similar. Stem Cel Res. 13 (2), 275-283. doi:10.1016/ j.scr.2014.07.006

Du, Y., Wang, J., Jia, J., Song, N., Xiang, C., Xu, J., et al. (2014). Human Hepatocytes with Drug Metabolic Function Induced from Fibroblasts by Lineage Reprogramming. Cell Stem Cell 14 (3), 394-403. doi:10.1016/j.stem.2014.01.008

Feaver, R. E., Cole, B. K., Lawson, M. J., Hoang, S. A., Marukian, S., Blackman, B. R., et al. (2016). Development of an In Vitro Human Liver System for Interrogating Nonalcoholic Steatohepatitis. JCI Insight 1 (20), e90954. doi:10.1172/ jci.insight.90954

Fontana, R. J., Hayashi, P. H., Gu, J., Reddy, K. R., Barnhart, H., Watkins, P. B., et al. (2014). Idiosyncratic Drug-Induced Liver Injury Is Associated with Substantial Morbidity and Mortality within 6 Months from Onset. Gastroenterology 147 (1), 96-108.e104. doi:10.1053/j.gastro.2014.03.045

Gerussi, A., Natalini, A., Antonangeli, F., Mancuso, C., Agostinetto, E., Barisani, D., et al. (2021). Immune-Mediated Drug-Induced Liver Injury: Immunogenetics and Experimental Models. Ijms 22 (9), 4557. doi:10.3390/ijms22094557

Gissen, P., and Arias, I. M. (2015). Structural and Functional Hepatocyte Polarity and Liver Disease. J. Hepatol. 63 (4), 1023-1037. doi:10.1016/j.jhep.2015.06.015

Glicklis, R., Merchuk, J. C., and Cohen, S. (2004). Modeling Mass Transfer in Hepatocyte Spheroids via Cell Viability, Spheroid Size, and Hepatocellular Functions. Biotechnol. Bioeng. 86 (6), 672-680. doi:10.1002/bit.20086

Gómez-Lechón, M. J., Tolosa, L., Conde, I., and Donato, M. T. (2014). Competency of Different Cell Models to Predict Human Hepatotoxic Drugs. Expert Opin. Drug Metab. Toxicol. 10 (11), 1553-1568. doi:10.1517/17425255.2014.967680

Gómez-Mariano, G., Matamala, N., Martínez, S., Justo, I., Marcacuzco, A., Jimenez, C., et al. (2020). Liver Organoids Reproduce Alpha-1 Antitrypsin Deficiency-Related Liver Disease. Hepatol. Int. 14 (1), 127-137. doi:10.1007/s12072-019-10007-y

Greene, C. M., Marciniak, S. J., Teckman, J., Ferrarotti, I., Brantly, M. L., Lomas, D. A., et al. (2016). al-Antitrypsin Deficiency. Nat. Rev. Dis. Primers 2, 16051. doi:10.1038/nrdp.2016.51

Grimes, D. R., Kelly, C., Bloch, K., and Partridge, M. (2014). A Method for Estimating the Oxygen Consumption Rate in Multicellular Tumour Spheroids. J. R. Soc. Interf. 11 (92), 20131124. doi:10.1098/rsif.2013.1124

Gripon, P., Rumin, S., Urban, S., Le Seyec, J., Glaise, D., Cannie, I., et al. (2002). Nonlinear Partial Differential Equations and Applications: Infection of a Human Hepatoma Cell Line by Hepatitis B Virus. Proc. Natl. Acad. Sci. 99 (24), 15655-15660. doi:10.1073/pnas.232137699

Gupta, N., Liu, J. R., Patel, B., Solomon, D. E., Vaidya, B., and Gupta, V. (2016). Microfluidics-based 3D Cell Culture Models: Utility in Novel Drug Discovery and Delivery Research. Bioeng. Translational Med. 1 (1), 63-81. doi:10.1002/ btm2.10013

Hendriks, D. F. G., Fredriksson Puigvert, L., Messner, S., Mortiz, W., and Ingelman-Sundberg, M. (2016). Hepatic 3D Spheroid Models for the Detection and Study of Compounds with Cholestatic Liability. Sci. Rep. 6 (1), 35434. doi:10.1038/srep35434

Hiemstra, S., Ramaiahgari, S. C., Wink, S., Callegaro, G., Coonen, M., Meerman, J., et al. (2019). High-throughput Confocal Imaging of Differentiated 3D Liverlike Spheroid Cellular Stress Response Reporters for Identification of DrugInduced Liver Injury Liability. Arch. Toxicol. 93 (10), 2895-2911. doi:10.1007/ s00204-019-02552-0

Hu, H., Gehart, H., Artegiani, B., LÖpez-Iglesias, C., Dekkers, F., Basak, O., et al. (2018). Long-Term Expansion of Functional Mouse and Human Hepatocytes as 3D Organoids. Cell 175 (6), 1591-1606.e1519. doi:10.1016/ j.cell.2018.11.013
Huang, P., Zhang, L., Gao, Y., He, Z., Yao, D., Wu, Z., et al. (2014). Direct Reprogramming of Human Fibroblasts to Functional and Expandable Hepatocytes. Cell Stem Cell 14 (3), 370-384. doi:10.1016/j.stem.2014.01.003

Huch, M., and Koo, B.-K. (2015). Modeling Mouse and Human Development Using Organoid Cultures. Development 142 (18), 3113-3125. doi:10.1242/ dev. 118570

Huch, M., Gehart, H., van Boxtel, R., Hamer, K., Blokzijl, F., Verstegen, M. M. A., et al. (2015). Long-term Culture of Genome-Stable Bipotent Stem Cells from Adult Human Liver. Cell 160 (1-2), 299-312. doi:10.1016/ j.cell.2014.11.050

Iansante, V., Mitry, R. R., Filippi, C., Fitzpatrick, E., and Dhawan, A. (2018). Human Hepatocyte Transplantation for Liver Disease: Current Status and Future Perspectives. Pediatr. Res. 83 (1), 232-240. doi:10.1038/pr.2017.284

Ingelman-Sundberg, M., Zhong, X.-B., Hankinson, O., Beedanagari, S., Yu, A.-M., Peng, L., et al. (2013). Potential Role of Epigenetic Mechanisms in the Regulation of Drug Metabolism and Transport. Drug Metab. Dispos. 41 (10), 1725-1731. doi:10.1124/dmd.113.053157

Ingelman-Sundberg, M. (2001). Genetic Susceptibility to Adverse Effects of Drugs and Environmental Toxicants. The Role of the CYP Family of Enzymes. Mutat. Res. 482 (1-2), 11-19. doi:10.1016/s0027-5107(01)00205-6

Khetani, S. R., Kanchagar, C., Ukairo, O., Krzyzewski, S., Moore, A., Shi, J., et al. (2013). Use of Micropatterned Cocultures to Detect Compounds that Cause Drug-Induced Liver Injury in Humans. Toxicol. Sci. 132 (1), 107-117. doi:10.1093/toxsci/kfs326

Kietzmann, T. (2019). Liver Zonation in Health and Disease: Hypoxia and Hypoxia-Inducible Transcription Factors as Concert Masters. Ijms 20 (9), 2347. doi:10.3390/ijms 20092347

Koido, M., Kawakami, E., Fukumura, J., Noguchi, Y., Ohori, M., Nio, Y., et al. (2020). Polygenic Architecture Informs Potential Vulnerability to DrugInduced Liver Injury. Nat. Med. 26 (10), 1541-1548. doi:10.1038/s41591020-1023-0

Kostrzewski, T., Cornforth, T., Snow, S. A., Ouro-Gnao, L., Rowe, C., Large, E. M., et al. (2017). Three-dimensional Perfused Human In Vitro Model of Nonalcoholic Fatty Liver Disease. Wjg 23 (2), 204-215. doi:10.3748/wjg.v23.i2.204

Kozyra, M., Johansson, I., Nordling, Å., Ullah, S., Lauschke, V. M., and IngelmanSundberg, M. (2018). Human Hepatic 3D Spheroids as a Model for Steatosis and Insulin Resistance. Sci. Rep. 8 (1), 14297. doi:10.1038/s41598-018-32722-6

Lauschke, V. M., Vorrink, S. U., Moro, S. M. L., Rezayee, F., Nordling, Å., Hendriks, D. F. G., et al. (2016). Massive Rearrangements of Cellular MicroRNA Signatures Are Key Drivers of Hepatocyte Dedifferentiation. Hepatology 64 (5), 1743-1756. doi:10.1002/hep.28780

Lauschke, V. M., Shafagh, R. Z., Hendriks, D. F. G., and Ingelman-Sundberg, M. (2019). 3D Primary Hepatocyte Culture Systems for Analyses of Liver Diseases, Drug Metabolism, and Toxicity: Emerging Culture Paradigms and Applications. Biotechnol. J. 14 (7), 1800347. doi:10.1002/biot.201800347

Lee, S. Y., and Sung, J. H. (2018). Gut-Liver on a Chip toward an In Vitro Model of Hepatic Steatosis. Biotechnol. Bioeng. 115 (11), 2817-2827. doi:10.1002/ bit.26793

Lemaigre, F. P. (2009). Mechanisms of Liver Development: Concepts for Understanding Liver Disorders and Design of Novel Therapies. Gastroenterology 137 (1), 62-79. doi:10.1053/j.gastro.2009.03.035

Li, F., Cao, L., Parikh, S., and Zuo, R. (2020). Three-Dimensional Spheroids with Primary Human Liver Cells and Differential Roles of Kupffer Cells in DrugInduced Liver Injury. J. Pharm. Sci. 109 (6), 1912-1923. doi:10.1016/ j.xphs.2020.02.021

Lin, C., and Khetani, S. R. (2016). Advances in Engineered Liver Models for Investigating Drug-Induced Liver Injury. Biomed. Res. Int. 2016, 1-20. doi: $10.1155 / 2016 / 1829148$

Lucifora, J., Durantel, D., Testoni, B., Hantz, O., Levrero, M., and Zoulim, F. (2010). Control of Hepatitis B Virus Replication by Innate Response of HepaRG Cells. Hepatology 51 (1), 63-72. doi:10.1002/hep.23230

Ma, X., Liu, J., Zhu, W., Tang, M., Lawrence, N., Yu, C., et al. (2018). 3D Bioprinting of Functional Tissue Models for Personalized Drug Screening and In Vitro Disease Modeling. Adv. Drug Deliv. Rev. 132, 235-251. doi:10.1016/j.addr.2018.06.011

Markova, S. M., De Marco, T., Bendjilali, N., Kobashigawa, E. A., Mefford, J., Sodhi, J., et al. (2013). Association of CYP2C $9 * 2$ with Bosentan-Induced Liver Injury. Clin. Pharmacol. Ther. 94 (6), 678-686. doi:10.1038/clpt.2013.143 
Mayati, A., Moreau, A., Le Vée, M., Bruyère, A., Jouan, E., Denizot, C., et al. (2018). Functional Polarization of Human Hepatoma HepaRG Cells in Response to Forskolin. Sci. Rep. 8 (1), 16115. doi:10.1038/s41598-018-34421-8

McQuitty, C. E., Williams, R., Chokshi, S., and Urbani, L. (2020). Immunomodulatory Role of the Extracellular Matrix within the Liver Disease Microenvironment. Front. Immunol. 11, 574276. doi:10.3389/fimmu.2020.574276

Mitani, S., Takayama, K., Nagamoto, Y., Imagawa, K., Sakurai, F., Tachibana, M., et al. (2017). Human ESC/iPSC-Derived Hepatocyte-like Cells Achieve Zonespecific Hepatic Properties by Modulation of WNT Signaling. Mol. Ther. 25 (6), 1420-1433. doi:10.1016/j.ymthe.2017.04.006

Mizoi, K., Arakawa, H., Yano, K., Koyama, S., Kojima, H., and Ogihara, T. (2020). Utility of Three-Dimensional Cultures of Primary Human Hepatocytes (Spheroids) as Pharmacokinetic Models. Biomedicines 8 (10), 374. doi:10.3390/biomedicines8100374

Nagamoto, Y., Tashiro, K., Takayama, K., Ohashi, K., Kawabata, K., Sakurai, F., et al. (2012). The Promotion of Hepatic Maturation of Human Pluripotent Stem Cells in 3D Co-culture Using Type I Collagen and Swiss 3T3 Cell Sheets. Biomaterials 33 (18), 4526-4534. doi:10.1016/j.biomaterials.2012.03.011

Nie, Y.-Z., Zheng, Y.-W., Ogawa, M., Miyagi, E., and Taniguchi, H. (2018). Human Liver Organoids Generated with Single Donor-Derived Multiple Cells rescue Mice from Acute Liver Failure. Stem Cel Res Ther 9 (1), 5. doi:10.1186/s13287-017-0749-1

Nuciforo, S., and Heim, M. H. (2021). Organoids to Model Liver Disease. JHEP Rep. 3 (1), 100198. doi:10.1016/j.jhepr.2020.100198

Nwosu, Z. C., Battello, N., Rothley, M., Piorońska, W., Sitek, B., Ebert, M. P., et al. (2018). Liver Cancer Cell Lines Distinctly Mimic the Metabolic Gene Expression Pattern of the Corresponding Human Tumours. J. Exp. Clin. Cancer Res. 37 (1), 211. doi:10.1186/s13046-018-0872-6

Ober, E. A., and Lemaigre, F. P. (2018). Development of the Liver: Insights into Organ and Tissue Morphogenesis. J. Hepatol. 68 (5), 1049-1062. doi:10.1016/ j.jhep.2018.01.005

Oliva-Vilarnau, N., Vorrink, S. U., Ingelman-Sundberg, M., and Lauschke, V. M. (2020). A 3D Cell Culture Model Identifies Wnt/ $\beta$-Catenin Mediated Inhibition of $\mathrm{P} 53$ as a Critical Step during Human Hepatocyte Regeneration. Adv. Sci. 7 (15), 2000248. doi:10.1002/advs.202000248

Olson, H., Betton, G., Robinson, D., Thomas, K., Monro, A., Kolaja, G., et al. (2000). Concordance of the Toxicity of Pharmaceuticals in Humans and in Animals. Regul. Toxicol. Pharmacol. 32 (1), 56-67. doi:10.1006/rtph.2000.1399

Ortega-Prieto, A. M., Skelton, J. K., Wai, S. N., Large, E., Lussignol, M., VizcayBarrena, G., et al. (2018). 3D Microfluidic Liver Cultures as a Physiological Preclinical Tool for Hepatitis B Virus Infection. Nat. Commun. 9 (1), 682. doi:10.1038/s41467-018-02969-8

Ott, L. M., Ramachandran, K., and Stehno-Bittel, L. (2017). An Automated Multiplexed Hepatotoxicity and CYP Induction Assay Using HepaRG Cells in 2D and 3D. Slas Discov: Adv. Sci. Drug Discov. 22 (5), 614-625. doi:10.1177/ 2472555217701058

Ouchi, R., Togo, S., Kimura, M., Shinozawa, T., Koido, M., Koike, H., et al. (2019). Modeling Steatohepatitis in Humans with Pluripotent Stem Cell-Derived Organoids. Cel Metab. 30 (2), 374-384 e376. doi:10.1016/j.cmet.2019.05.007

Pek, N. M. Q., Liu, K. J., Nichane, M., and Ang, L. T. (2021). Controversies Surrounding the Origin of Hepatocytes in Adult Livers and the In Vitro Generation or Propagation of Hepatocytes. Cell Mol. Gastroenterol. Hepatol. 11 (1), 273-290. doi:10.1016/j.jcmgh.2020.09.016

Peng, L., and Zhong, X. (2015). Epigenetic Regulation of Drug Metabolism and Transport. Acta Pharm. Sin. B 5 (2), 106-112. doi:10.1016/j.apsb.2015.01.007

Pericleous, M., Kelly, C., Wang, T., Livingstone, C., and Ala, A. (2017). Wolman's Disease and Cholesteryl Ester Storage Disorder: the Phenotypic Spectrum of Lysosomal Acid Lipase Deficiency. Lancet Gastroenterol. Hepatol. 2 (9), 670-679. doi:10.1016/s2468-1253(17)30052-3

Pettinato, G., Lehoux, S., Ramanathan, R., Salem, M. M., He, L.-X., Muse, O., et al. (2019). Generation of Fully Functional Hepatocyte-like Organoids from Human Induced Pluripotent Stem Cells Mixed with Endothelial Cells. Sci. Rep. 9 (1), 8920. doi:10.1038/s41598-019-45514-3

Prior, N., Inacio, P., and Huch, M. (2019). Liver Organoids: from Basic Research to Therapeutic Applications. Gut 68 (12), 2228-2237. doi:10.1136/gutjnl-2019-319256

Proctor, W. R., Foster, A. J., Vogt, J., Summers, C., Middleton, B., Pilling, M. A., et al. (2017). Utility of Spherical Human Liver Microtissues for Prediction of Clinical Drug-Induced Liver Injury. Arch. Toxicol. 91 (8), 2849-2863. doi:10.1007/s00204-017-2002-1
Raab, S., Klingenstein, M., Liebau, S., and Linta, L. (2014). A Comparative View on Human Somatic Cell Sources for iPSC Generation. Stem Cell Int. 2014, 1-12. doi:10.1155/2014/768391

Ramaiahgari, S. C., den Braver, M. W., Herpers, B., Terpstra, V., Commandeur, J. N. M., van de Water, B., et al. (2014). A 3D In Vitro Model of Differentiated HepG2 Cell Spheroids with Improved Liver-like Properties for Repeated Dose High-Throughput Toxicity Studies. Arch. Toxicol. 88 (5), 1083-1095. doi:10.1007/s00204-014-1215-9

Ramaiahgari, S. C., Waidyanatha, S., Dixon, D., DeVito, M. J., Paules, R. S., and Ferguson, S. S. (2017). From the Cover: Three-Dimensional (3D) HepaRG Spheroid Model with Physiologically Relevant Xenobiotic Metabolism Competence and Hepatocyte Functionality for Liver Toxicity Screening. Toxicol. Sci. 159 (1), 124-136. doi:10.1093/toxsci/kfx122

Ramasamy, T. S., Yu, J. S. L., Selden, C., Hodgson, H., and Cui, W. (2013). Application of Three-Dimensional Culture Conditions to Human Embryonic Stem Cell-Derived Definitive Endoderm Cells Enhances Hepatocyte Differentiation and Functionality. Tissue Eng. A 19 (3-4), 360-367. doi:10.1089/ten.tea.2012.0190

Ramboer, E., Vanhaecke, T., Rogiers, V., and Vinken, M. (2015). Immortalized Human Hepatic Cell Lines for In Vitro Testing and Research Purposes. Methods Mol. Biol. 1250, 53-76. doi:10.1007/978-1-4939-2074-7_4

Rettie, A. E., Wienkers, L. C., Gonzalez, F. J., Trager, W. F., and Korzekwa, K. R. (1994). Impaired (S)-warfarin Metabolism Catalysed by the R144C Allelic Variant of CYP2C9. Pharmacogenetics 4 (1), 39-42. doi:10.1097/00008571199402000-00005

Reuben, A., Koch, D. G., and Lee, W. M. (2010). Drug-induced Acute Liver Failure: Results of a U.S. Multicenter, Prospective Study. Hepatology 52 (6), 2065-2076. doi:10.1002/hep.23937

Rodríguez-Hernández, M. A., Chapresto-Garzón, R., Cadenas, M., NavarroVillarán, E., Negrete, M., Gómez-Bravo, M. A., et al. (2020). Differential Effectiveness of Tyrosine Kinase Inhibitors in 2D/3D Culture According to Cell Differentiation, P53 Status and Mitochondrial Respiration in Liver Cancer Cells. Cell Death Dis. 11 (5), 339. doi:10.1038/s41419-020-2558-1

Roelandt, P., Obeid, S., Paeshuyse, J., Vanhove, J., Van Lommel, A., Nahmias, Y., et al. (2012). Human Pluripotent Stem Cell-Derived Hepatocytes Support Complete Replication of Hepatitis C Virus. J. Hepatol. 57 (2), 246-251. doi:10.1016/j.jhep.2012.03.030

Romeo, S., Kozlitina, J., Xing, C., Pertsemlidis, A., Cox, D., Pennacchio, L. A., et al. (2008). Genetic Variation in PNPLA3 Confers Susceptibility to Nonalcoholic Fatty Liver Disease. Nat. Genet. 40 (12), 1461-1465. doi:10.1038/ng.257

Roth, A. D., and Lee, M.-Y. (2017). Idiosyncratic Drug-Induced Liver Injury (IDILI): Potential Mechanisms and Predictive Assays. Biomed. Res. Int. 2017, 1-23. doi:10.1155/2017/9176937

Rowe, C., Gerrard, D. T., Jenkins, R., Berry, A., Durkin, K., Sundstrom, L., et al. (2013). Proteome-wide Analyses of Human Hepatocytes during Differentiation and Dedifferentiation. Hepatology 58 (2), 799-809. doi:10.1002/hep.26414

Rubin, K., Janefeldt, A., Andersson, L., Berke, Z., Grime, K., and Andersson, T. B. (2015). HepaRG Cells as Human-Relevant In Vitro Model to Study the Effects of Inflammatory Stimuli on Cytochrome P450 Isoenzymes. Drug Metab. Dispos. 43 (1), 119-125. doi:10.1124/dmd.114.059246

Ruoß, M., Damm, G., Vosough, M., Ehret, L., Grom-Baumgarten, C., Petkov, M., et al. (2019). Epigenetic Modifications of the Liver Tumor Cell Line HepG2 Increase Their Drug Metabolic Capacity. Ijms 20 (2), 347. doi:10.3390/ ijms 20020347

Schmelzer, E., Zhang, L., Bruce, A., Wauthier, E., Ludlow, J., Yao, H.-l., et al. (2007). Human Hepatic Stem Cells from Fetal and Postnatal Donors. J. Exp. Med. 204 (8), 1973-1987. doi:10.1084/jem.20061603

Schwartz, R. E., Trehan, K., Andrus, L., Sheahan, T. P., Ploss, A., Duncan, S. A., et al. (2012). Modeling Hepatitis C Virus Infection Using Human Induced Pluripotent Stem Cells. Proc. Natl. Acad. Sci. 109 (7), 2544-2548. doi:10.1073/ pnas.1121400109

Sells, M. A., Chen, M. L., and Acs, G. (1987). Production of Hepatitis B Virus Particles in Hep G2 Cells Transfected with Cloned Hepatitis B Virus DNA. Proc. Natl. Acad. Sci. 84 (4), 1005-1009. doi:10.1073/pnas.84.4.1005

Shah, F., Leung, L., Barton, H. A., Will, Y., Rodrigues, A. D., Greene, N., et al. (2015). Setting Clinical Exposure Levels of Concern for Drug-Induced Liver 
Injury (DILI) Using Mechanistic In Vitro Assays. Toxicol. Sci. 147 (2), 500-514. doi:10.1093/toxsci/kfv152

Shinozawa, T., Kimura, M., Cai, Y., Saiki, N., Yoneyama, Y., Ouchi, R., et al. (2021). High-Fidelity Drug-Induced Liver Injury Screen Using Human Pluripotent Stem Cell-Derived Organoids. Gastroenterology 160 (3), 831-846,e810. doi:10.1053/j.gastro.2020.10.002

Shlomai, A., Schwartz, R. E., Ramanan, V., Bhatta, A., de Jong, Y. P., Bhatia, S. N., et al. (2014). Modeling Host Interactions with Hepatitis B Virus Using Primary and Induced Pluripotent Stem Cell-Derived Hepatocellular Systems. Proc. Natl. Acad. Sci. 111 (33), 12193-12198. doi:10.1073/pnas.1412631111

Sison-Young, R. L. C., Mitsa, D., Jenkins, R. E., Mottram, D., Alexandre, E., Richert, L., et al. (2015). Comparative Proteomic Characterization of 4 Human LiverDerived Single Cell Culture Models Reveals Significant Variation in the Capacity for Drug Disposition, Bioactivation, and Detoxication. Toxicol. Sci. 147 (2), 412-424. doi:10.1093/toxsci/kfv136

So, J., Kim, A., Lee, S.-H., and Shin, D. (2020). Liver Progenitor Cell-Driven Liver Regeneration. Exp. Mol. Med. 52 (8), 1230-1238. doi:10.1038/s12276-020-0483-0

Takahashi, K., and Yamanaka, S. (2006). Induction of Pluripotent Stem Cells from Mouse Embryonic and Adult Fibroblast Cultures by Defined Factors. Cell 126 (4), 663-676. doi:10.1016/j.cell.2006.07.024

Takahashi, K., Tanabe, K., Ohnuki, M., Narita, M., Ichisaka, T., Tomoda, K., et al. (2007). Induction of Pluripotent Stem Cells from Adult Human Fibroblasts by Defined Factors. Cell 131 (5), 861-872. doi:10.1016/j.cell.2007.11.019

Takayama, K., Inamura, M., Kawabata, K., Sugawara, M., Kikuchi, K., Higuchi, M., et al. (2012). Generation of Metabolically Functioning Hepatocytes from Human Pluripotent Stem Cells by FOXA2 and HNF1a Transduction. J. Hepatol. 57 (3), 628-636. doi:10.1016/j.jhep.2012.04.038

Takayama, K., Kawabata, K., Nagamoto, Y., Kishimoto, K., Tashiro, K., Sakurai, F., et al. (2013). 3D Spheroid Culture of hESC/hiPSC-Derived Hepatocyte-like Cells for Drug Toxicity Testing. Biomaterials 34 (7), 1781-1789. doi:10.1016/ j.biomaterials.2012.11.029

Takayama, K., Morisaki, Y., Kuno, S., Nagamoto, Y., Harada, K., Furukawa, N., et al. (2014). Prediction of Interindividual Differences in Hepatic Functions and Drug Sensitivity by Using Human iPS-Derived Hepatocytes. Proc. Natl. Acad. Sci. USA 111 (47), 16772-16777. doi:10.1073/pnas.1413481111

Takebe, T., Sekine, K., Enomura, M., Koike, H., Kimura, M., Ogaeri, T., et al. (2013). Vascularized and Functional Human Liver from an iPSC-Derived Organ Bud Transplant. Nature 499 (7459), 481-484. doi:10.1038/ nature12271

Tarlow, B. D., Pelz, C., Naugler, W. E., Wakefield, L., Wilson, E. M., Finegold, M. J., et al. (2014). Bipotential Adult Liver Progenitors Are Derived from Chronically Injured Mature Hepatocytes. Cell Stem Cell. 15 (5), 605-618. doi:10.1016/ j.stem.2014.09.008

Thiagarajan, P., Bawden, S. J., and Aithal, G. P. (2021). Metabolic Imaging in NonAlcoholic Fatty Liver Disease: Applications of Magnetic Resonance Spectroscopy. Jcm 10 (4), 632. doi:10.3390/jcm10040632

Touboul, T., Hannan, N. R. F., Corbineau, S., Martinez, A., Martinet, C., Branchereau, S., et al. (2010). Generation of Functional Hepatocytes from Human Embryonic Stem Cells under Chemically Defined Conditions that Recapitulate Liver Development. Hepatology 51 (5), 1754-1765. doi:10.1002/hep.23506

Treyer, A., and Müsch, A. (2013). Hepatocyte Polarity. Compr. Physiol. 3 (1), 243-287. doi:10.1002/cphy.c120009

Underhill, G. H., and Khetani, S. R. (2018). Bioengineered Liver Models for Drug Testing and Cell Differentiation Studies. Cell Mol. Gastroenterol. Hepatol. 5 (3), 426-439 e421. doi:10.1016/j.jcmgh.2017.11.012

Urban, T., Aithal, G., and Daly, A. (2014). Genetic Basis of Drug-Induced Liver Injury: Present and Future. Semin. Liver Dis. 34 (2), 123-133. doi:10.1055/s-0034-1375954

Vierbuchen, T., and Wernig, M. (2012). Molecular Roadblocks for Cellular Reprogramming. Mol. Cel 47 (6), 827-838. doi:10.1016/ j.molcel.2012.09.008

Vorrink, S. U., Ullah, S., Schmidt, S., Nandania, J., Velagapudi, V., Beck, O., et al. (2017). Endogenous and Xenobiotic Metabolic Stability of Primary Human Hepatocytes in Long-term 3D Spheroid Cultures Revealed by a Combination of Targeted and Untargeted Metabolomics. FASEB j. 31 (6), 2696-2708. doi:10.1096/fj.201601375R

Vorrink, S. U., Zhou, Y., Ingelman-Sundberg, M., and Lauschke, V. M. (2018). Prediction of Drug-Induced Hepatotoxicity Using Long-Term Stable Primary
Hepatic 3D Spheroid Cultures in Chemically Defined Conditions. Toxicol. Sci. 163 (2), 655-665. doi:10.1093/toxsci/kfy058

Wang, W. W., Khetani, S. R., Krzyzewski, S., Duignan, D. B., and Obach, R. S. (2010). Assessment of a Micropatterned Hepatocyte Coculture System to Generate Major Human Excretory and Circulating Drug Metabolites. Drug Metab. Dispos. 38 (10), 1900-1905. doi:10.1124/dmd.110.034876

Wang, Z., Li, W., Jing, H., Ding, M., Fu, G., Yuan, T., et al. (2019). Generation of Hepatic Spheroids Using Human Hepatocyte-Derived Liver Progenitor-like Cells for Hepatotoxicity Screening. Theranostics 9 (22), 6690-6705. doi:10.7150/thno. 34520

Ware, B. R., McVay, M., Sunada, W. Y., and Khetani, S. R. (2017). Exploring Chronic Drug Effects on Microengineered Human Liver Cultures Using Global Gene Expression Profiling. Toxicol. Sci. 157 (2), 387-398. doi:10.1093/toxsci/kfx059

Wiktor, S. Z., and Hutin, Y. J.-F. (2016). The Global burden of Viral Hepatitis: Better Estimates to Guide Hepatitis Elimination Efforts. Lancet 388 (10049), 1030-1031. doi:10.1016/s0140-6736(16)31018-2

Wink, S., Hiemstra, S. W., Huppelschoten, S., Klip, J. E., and van de Water, B. (2018). Dynamic Imaging of Adaptive Stress Response Pathway Activation for Prediction of Drug Induced Liver Injury. Arch. Toxicol. 92 (5), 1797-1814. doi:10.1007/s00204-018-2178-z

Xiang, C., Du, Y., Meng, G., Soon Yi, L., Sun, S., Song, N., et al. (2019). Long-term Functional Maintenance of Primary Human Hepatocytes In Vitro. Science 364 (6438), 399-402. doi:10.1126/science.aau7307

Xu, J. J., Henstock, P. V., Dunn, M. C., Smith, A. R., Chabot, J. R., and de Graaf, D. (2008). Cellular Imaging Predictions of Clinical Drug-Induced Liver Injury. Toxicol. Sci. 105 (1), 97-105. doi:10.1093/toxsci/kfn109

Yan, H., Zhong, G., Xu, G., He, W., Jing, Z., Gao, Z., et al. (2012). Sodium Taurocholate Cotransporting Polypeptide Is a Functional Receptor for Human Hepatitis B and D Virus. Elife 1, e00049. doi:10.7554/eLife.00049

Yang, H., Sun, L., Pang, Y., Hu, D., Xu, H., Mao, S., et al. (2021). Three-dimensional Bioprinted Hepatorganoids Prolong Survival of Mice with Liver Failure. Gut 70 (3), 567-574. doi:10.1136/gutjnl-2019-319960

Yanger, K., Knigin, D., Zong, Y., Maggs, L., Gu, G., Akiyama, H., et al. (2014). Adult Hepatocytes Are Generated by Self-Duplication rather Than Stem Cell Differentiation. Cell Stem Cell 15 (3), 340-349. doi:10.1016/ j.stem.2014.06.003

Zhang, J., Zhao, Y., Xu, C., Hong, Y., Lu, H., Wu, J., et al. (2014). Association between Serum Free Fatty Acid Levels and Nonalcoholic Fatty Liver Disease: a Cross-Sectional Study. Sci. Rep. 4 (1), 5832. doi:10.1038/ srep05832

Zhou, Y., Shen, J. X., and Lauschke, V. M. (2019). Comprehensive Evaluation of Organotypic and Microphysiological Liver Models for Prediction of DrugInduced Liver Injury. Front. Pharmacol. 10, 1093. doi:10.3389/ fphar.2019.01093

Zhou, S.-F. (2009). Polymorphism of Human Cytochrome P450 2D6 and its Clinical Significance. Clin. Pharmacokinet. 48 (11), 689-723. doi:10.2165/ 11318030-000000000-00000

Zong, Y., Panikkar, A., Xu, J., Antoniou, A., Raynaud, P., Lemaigre, F., et al. (2009). Notch Signaling Controls Liver Development by Regulating Biliary Differentiation. Development 136 (10), 1727-1739. doi:10.1242/dev.029140

Conflict of Interest: The author declares that the research was conducted in the absence of any commercial or financial relationships that could be construed as a potential conflict of interest.

Publisher's Note: All claims expressed in this article are solely those of the authors and do not necessarily represent those of their affiliated organizations, or those of the publisher, the editors, and the reviewers. Any product that may be evaluated in this article, or claim that may be made by its manufacturer, is not guaranteed or endorsed by the publisher.

Copyright $(02021 \mathrm{Xu}$. This is an open-access article distributed under the terms of the Creative Commons Attribution License (CC BY). The use, distribution or reproduction in other forums is permitted, provided the original author $(s)$ and the copyright owner(s) are credited and that the original publication in this journal is cited, in accordance with accepted academic practice. No use, distribution or reproduction is permitted which does not comply with these terms. 